\title{
About the lithospheric structure of central Tibet, based on seismic data from the INDEPTH III profile
}

\author{
Rolf Meissner $^{\mathrm{a}, *}$, Frederik Tilmann ${ }^{\mathrm{b}, 1}$, Seth Haines ${ }^{\mathrm{c}}$ \\ ${ }^{a}$ Institute of Geosciences, Christian Albrechts University, Otto Hahn Platz 1, Kiel, D-24118, Germany \\ ${ }^{\mathrm{b}}$ GEOMAR, Kiel, Germany \\ ${ }^{\mathrm{c}}$ Geoscience, Stanford University, USA
}

Received 27 November 2002; accepted 5 November 2003

\begin{abstract}
Signals from 11 shots and 8 earthquakes, and numerous teleseismic events were recorded along the $400-\mathrm{km}$ seismic line INDEPTH III in central Tibet and interpreted together with previous seismic and tectonic data. The abnormal behavior of various mantle phases reveals a complex Moho-transition zone, especially in the northern part of the line, in the Changtang Block, where the lower crust and the mantle show unusually low velocities, a shingled appearance of $P_{n}$ and no low-velocity layer in the upper crust. The strong east-west anisotropy in the Changtang Block is related to an easterly escape movement of the whole lithosphere, facilitated by the warm and weak layers in the lower crust and the upper mantle, bounded apparently by two prominent west-east running fault zones.
\end{abstract}

(C) 2004 Elsevier B.V. All rights reserved.

Keywords: Central Tibet; Crust-mantle transition; Refraction seismics; Anisotropy and tectonic escape

\section{Introduction}

A 400-km seismic wide-angle profile (INDEPTH III) was collected in summer 1998 in central Tibet. Three component broad-band seismometer stations remained on the profile up to summer 1999 for studies of teleseismic events and local earthquakes. During the active shooting phase, 11 large shots delivered seismic signals to the 62 seismometers, creating a dense network of overlapping travel time branches. Based on the seismic data of INDEPTH III, a number of papers were recently published: Huang et al. (2000)

\footnotetext{
* Corresponding author.

E-mail address: rmeissner@email.uni-kiel.de (R. Meissner).

${ }^{1}$ Now at: University Cambridge, England.
}

report on the seismic anisotropy in central Tibet and its correlation to tectonics, based on teleseismic studies, and Zhao et al. (2001) report on modeling the crustal structure in central Tibet from analyzing travel times from the 11 big shots along INDEPTH III. Rapine et al. (2003) constrain the regional scale crustal structure in Tibet based on surface wave dispersion analysis; Haines et al. (2003) concentrate on the shot-point data of INDEPTH III and deep crustal processes; and Kind et al. (2002) present discontinuity images of the mantle, based on the migration of receiver functions and show that the Poisson ratio is almost normal in north central Tibet.

Although the above-mentioned papers cover the most important geologic topics in central Tibet, we feel that tectonic questions about structure and evo- 
lution have yet to be solved. We list a few of the remaining topics which will be addressed in this paper: (1) We give an alternative interpretation of the seismic wide-angle data, based on a panel of overlapping, controlled travel time branches, especially studying the area of the Banggong-Nuijang Suture

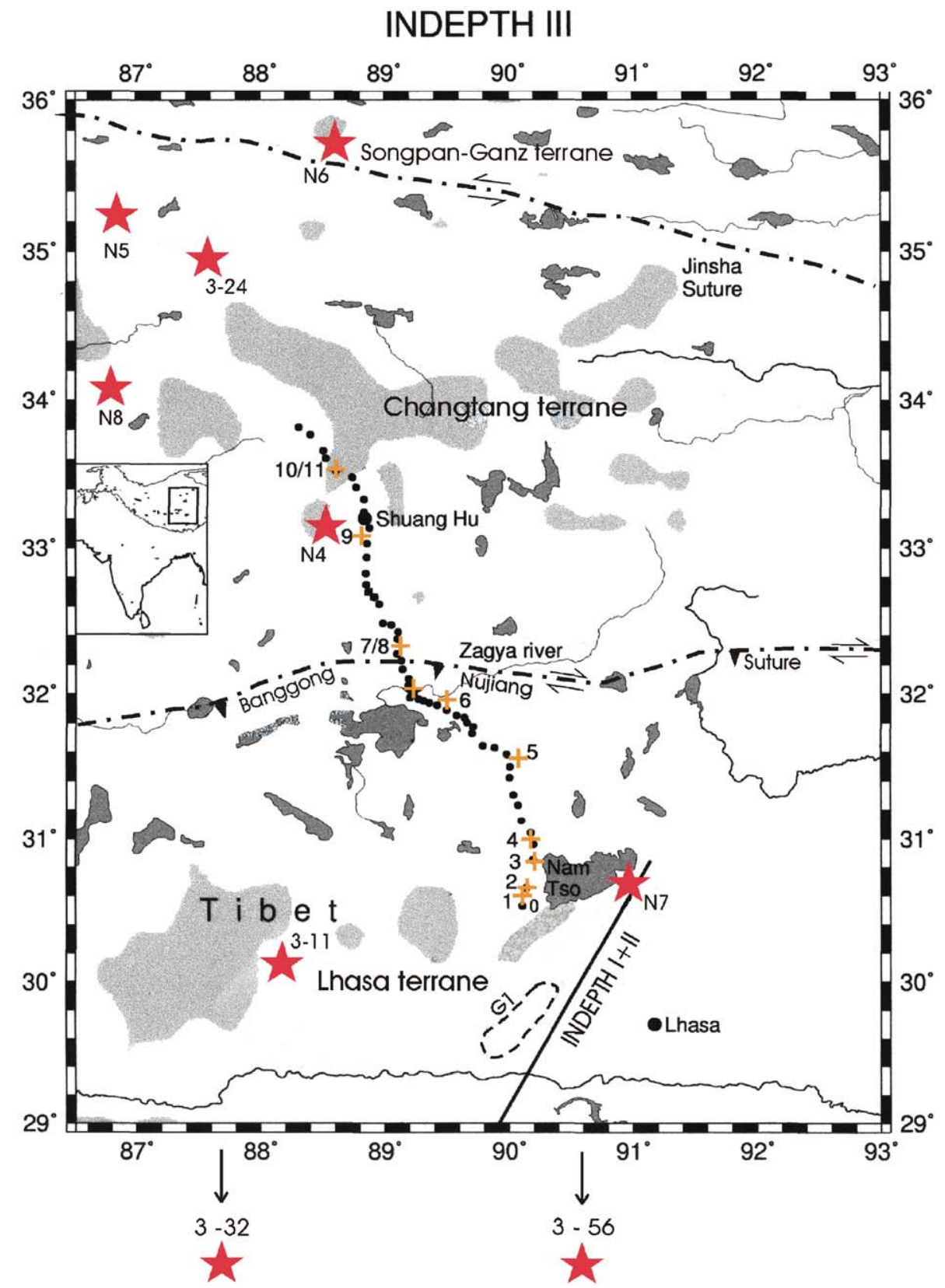

Fig. 1. The INDEPTH III-seismic profile and the position of nearby earthquakes, used for interpretation. Elevation of the profile is always $>4.500 \mathrm{~m}$. Small dots: seismograph stations. Small crosses: shot points with numbers. Big stars: earthquakes used for (later) interpretation. Dark gray areas: lakes. Light gray: areas with elevations higher than $5.500 \mathrm{~m}$. Profiles INDEPTH I and II indicated. G1 = common depth area of GEDEPTH wide-angle experiment. 
(BNS). (2) We add new seismological data from eight local earthquakes around INDEPTH III and also use overlapping travel time branches. (3) We report on the low crustal velocities in the Changtang Block and the strange behavior of the mantle phases $\mathrm{P}_{\mathrm{M}} \mathrm{P}$ and $\mathrm{P}_{\mathrm{n}}$. (4) We study the crust-mantle transition (at a depth of $\sim 70 \mathrm{~km}$ ) and argue that a smooth velocity gradient zone in the south and a heterogeneous zone in the north seem to characterize the Moho. (5) We interpret the strong SKS-anisotropy in the Changtang Block as indicating massive lithospheric (not only crustal) escape to the east. (6) We discuss the nature of crustal doubling in Tibet.

The topics (1) to (6) addressed above are rooted in a huge amount of geophysical, geodetic and geological investigations, starting with a tectonic overview of Argand (1924), later followed by plate tectonic considerations by Powel and Conaghan (1973), Dewey and Burke (1973), Molnar and Tapponier (1975), Tapponnier (1981, 1990), Le Pichon et al. (1997) and Tapponier et al. (2001). Considerable field activity started in the 1970s, and seismic/seismological studies were carried out in the 1980s and 1990s (Jia et al., 1981; Barazangi and Ni, 1982; Hirn et al., 1984; Coward et al., 1988; Beghoul et al., 1993; Hirn et al., 1995; Sapin and Hirn, 1997), always accompanied by general tectonic and rheological studies (Zhao and Morgan, 1985, 1987; Beghoul et al., 1993; Westaway, 1995). Regarding the crustal and lithospheric structure, the International Depth Profiling of Tibet and the Himalaya (INDEPTH project), starting in 1992, played a special role in collecting new details (INDEPTH Project Team et al., 1993; Nelson et al., 1996). In 1998, INDEPTH was continued to central Tibet (INDEPTH III, see Fig. 1). The project was not restricted to seismic methods and included also electromagnetic, geologic mapping and seismologic studies (Makowski and Klemperer, 1999).

Many hard facts about crustal thickness and lithospheric velocity structure were derived from the various INDEPTH campaigns. The Tibetan Plateau with an average elevation of between 4 and $5 \mathrm{~km}$ and an area of nearly $2000 \times 1000 \mathrm{~km}$ is not only the highest and largest plateau on earth but also has turned out to have the largest regional crustal thickness of $\sim 70 \mathrm{~km}$. It has become widely accepted that its origin is a product of the long-time collision between the Indian subcontinent and the Asian continent, a process which is still going on today (Dewey and Burke, 1973; Ratschbacher, 1996). Details of its evolution, however, are still hotly debated. Beghoul et al. (1993) and KolaOjo and Meissner (2001) discuss the main evolutionary models of the Tibetan plateau. It seems that the hydraulic pump model (Zhao and Morgan, 1985, 1987; Westaway, 1995) forms the basis for other models, e.g., for the tectonic escape model (Molnar and Tapponier, 1975; Tapponnier, 1981, 1990) and especially for the underthrusting (intrusion) model, going back to Argand (1924), modified by Powel and Conaghan (1973) and Powel (1986) and supported by new seismological studies (Beghoul et al., 1993). The weak rheology of a thick crust dictates that it is easily compressed and thickened, possibly including some shear zones in the rigid upper crust and that it is also easily intruded, especially in the weak lower part, perhaps by an indentor like the (cold) Indian subcrustal lithosphere from the south (Kosarev et al., 1999). Both processes, the overthickening and the indentation, lead to a tectonic escape of material to the east under the squeeze of the N-S compression (Tapponnier, 1981, 1990; Meissner et al., 2002). New arguments for the tectonic escape of central Tibet come from the strong SKS anisotropy (Huang et al., 2000; McNamara et al., 1994; Herquel et al., 1995).

\section{A new evaluation of the seismic wide-angle data along INDEPTH III}

As mentioned in the Introduction section and described in detail in Zhao et al. (2001), 11 big shots were fired and their signals were recorded by the 62 seismometers along the $400-\mathrm{km}$ long line of INDEPTH III (see Fig. 1). Five record sections of the vertical components of the geophones with some correlation are contained in Zhao et al. (2001). All record sections have been band-passed filtered (2-12 $\mathrm{Hz}$ ) and normalized. We display one of the record sections (shot-point 3) in Fig. 2. It is one of the best sections and contains refracted and reflected crustal phases, among them a clear $\mathrm{P}_{\mathrm{M}} \mathrm{P}$ wave at a distance between 180 and $350 \mathrm{~km}$. There are other peculiarities: about $20-30 \mathrm{~km}$ south of the BNS at $150 \mathrm{~km}$ offset the $\mathrm{P}_{\mathrm{g}}$ wave seems to end. An intra-crustal phase is observed between 100 and $150 \mathrm{~km}$ and also seems to disappear here. There is a time delay of 


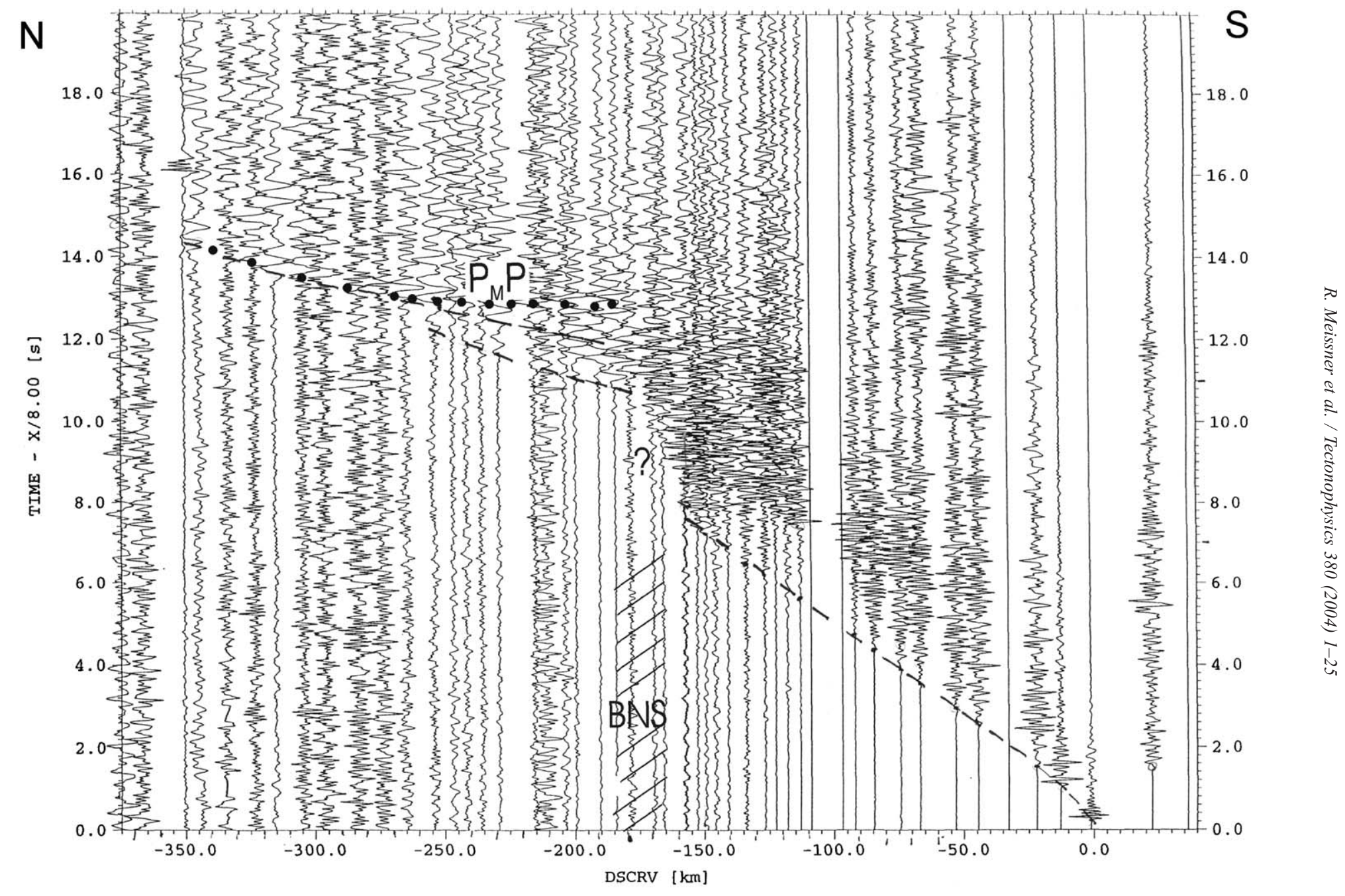

Fig. 2. Record section of signals from shot-point 3 (vertical component). Reduced travel times versus offset from the shot in km. Signals are band-pass filtered (2-12 Hz). The BNS fault zone system is indicated. 
about $3 \mathrm{~s}$ before the next phase starts. In general, such a big "jump" corresponds to a low velocity zone (LVZ), with a horizontal or oblique (even vertical) orientation, but some other possibilities are mentioned in the Discussion section.

We plotted all travel time data in an unreduced, composite travel time diagram (Fig. 3). We observe that all southern shot-points produce a large delay (jump) when crossing the area of the BNS (see travel time data of shot-points $1,2,3,4,5$, i.e., the signals from all shot-points south of the BNS). The signals from shot-point 6 , only $30 \mathrm{~km}$ south of the BNS in the Lumpola valley, have strong near-surface undulations with a very small velocity (slightly above $5 \mathrm{~km} / \mathrm{s}$ ), but nearly no jump when crossing the BNS area. The shot-points north of the BNS $(7,8,9,10,11)$ show only very small travel time anomalies or delays on their southward branches. Branches from shot-points 9 and 10 southward show an interruption, combined with a small travel time delay when crossing the BNS.

In general, it has to be stressed that all the southern shot-points ( 1 to 5 ) have their large jumps not at comparable travel times (horizontal LVZ), but at the same location, i.e., near the BNS. This co-incidence in location means that around the BNS, at least in the upper and middle crust, there is a near vertical LVZ,

NNW
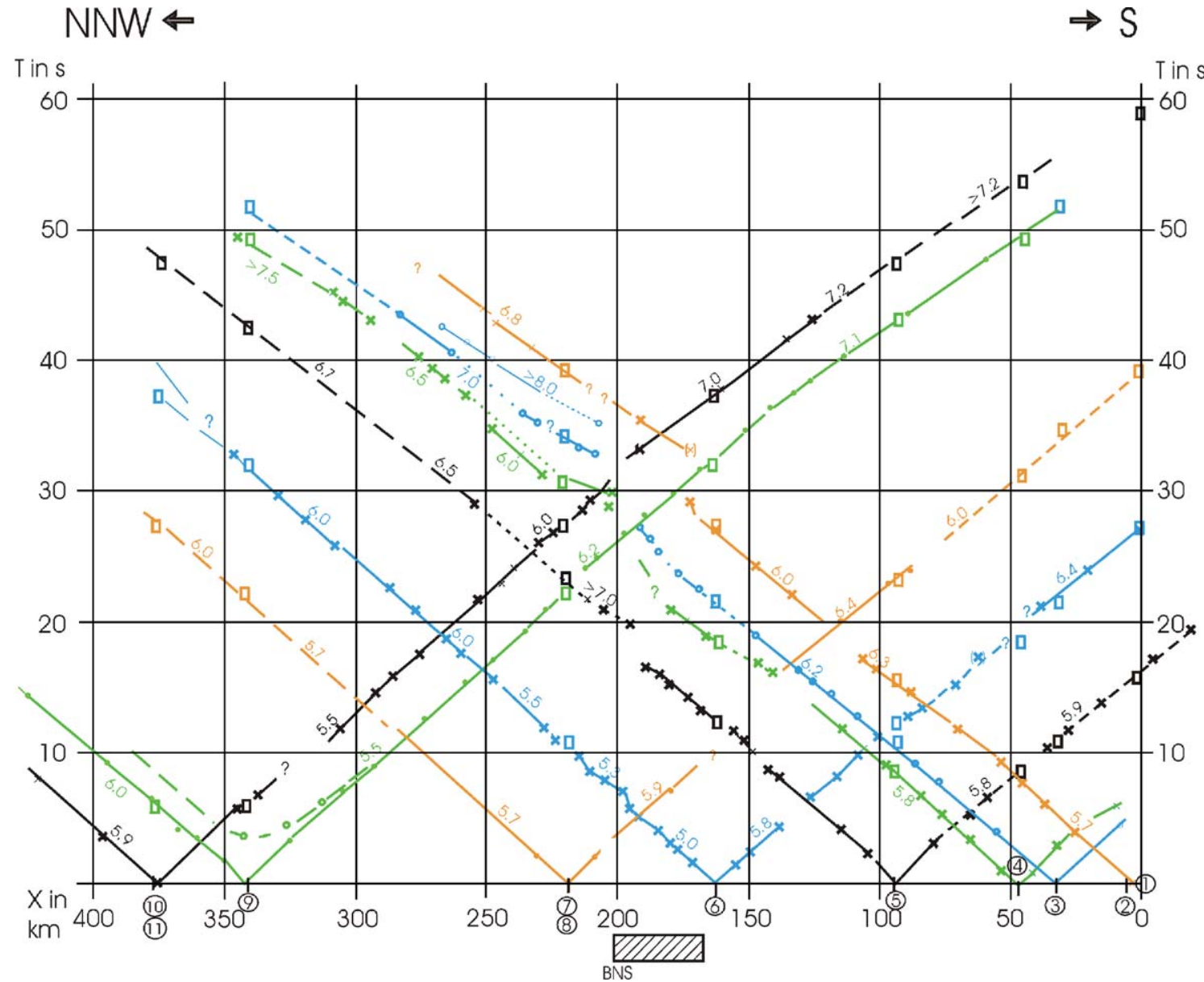

Fig. 3. Unreduced travel-time diagram of $\mathrm{P}_{\mathrm{g}}$-waves, showing overlapping travel-time branches, permitting the construction of reciprocal times and an artificial extension of travel time branches (dashed); BNS system indicated. Large numbers on the $x$-axis: distance along the profile in kilometers. Small numbers in circles: location of shot-points. Numbers along travel-time branches: apparent velocities in kilometers per second. Small boxes along the travel-time curves: reciprocal times. 
most probably a fault zone. Zhao et al. (2001) and Haines et al. (2003) also have mapped a zone of very low velocities around the BNS, but did not postulate a fault zone in their interpretations. About $20-30 \mathrm{~km}$ south of the BNS, in the Lumpola valley, along the Karakorum-Jiali Fault (KJF), deep-reaching shear deformation is suspected (Huang et al., 2000). The authors claim that this system pervades the whole crust and that shear deformation most likely reaches into the subcrustal lithosphere as well. The KJF is another candidate for the presence of a near-vertical fault zone, possibly interacting with the BNS (see paragraph on anisotropy), but as we do not know about details of the lithospheric structure we shall speak in the following of the BNS system when dealing with the extremely low P-velocities near the surface and the considerable jumps in the $\mathrm{P}$ travel times.

Our unreduced, composite diagram has the advantage (1) that travel time branches do not overlap and (2) that many control points in the form of identical reciprocal times are available and (3) that any irregularities in the travel tines (for instance jumps) can be easily related to a mainly horizontal (same times) or a mainly vertical (same location) anomaly (jump). With the help of the reciprocal times large branches of artificial travel times could be created (e.g., those from shot-points 9 and 10), and additional information on the velocities in the deeper crust could be obtained. The observation that our panel shows the jumps at approximately the same location is a very strong argument for the existence of a near vertical LVZ. Fig. 3 shows all the crustal travel time data along INDEPTH III except for the three $\mathrm{P}_{\mathrm{M}} \mathrm{P}$ events. These $\mathrm{P}_{\mathrm{M}} \mathrm{P}$ arrivals are clearly visible only on the record sections from shot-points 3 and 4 in the south and shot-point 10 in the north. Please note that none of the shot-points produced a $\mathrm{P}_{\mathrm{n}}$-phase or a discernable precritical $\mathrm{P}_{\mathrm{M}} \mathrm{P}$.

The crustal velocity-depth structure along the profile was calculated using a ray tracing method (Zelt and Smith, 1992).The velocity structure which will be shown later (Fig. 12) does not deviate very much from the diagram in Zhao et al. (2001), except for the area around the BNS system and for the crustmantle transition zone (to be discussed later). Taking into account the difference in the travel time jumps for the southern and the northern travel branches (seismic

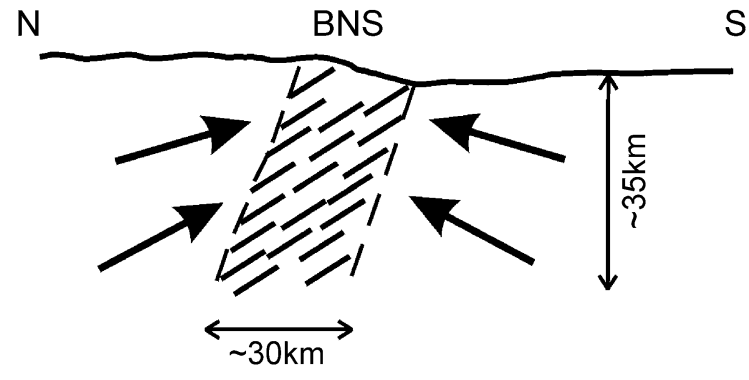

Fig. 4. Model of the suspected fault zone in the middle of INDEPTH III: the BNS system. Dashes inside fault-zone: possible fast axes of anisotropic matrix. Big arrows outside fault-zone: assumed direction of arriving seismic rays.

rays from the south show larger delays at the BNS), we modeled the BNS system with a slight northerly dip and with an assumed anisotropy which cause rays from the south to be much delayed while rays from the north might take advantage of the layered, anisotropic, north-dipping structure (see Fig. 4). This model explains the low velocities and the differences in the travel time jumps. The assumption of a northerly dip would also be in agreement with the presence of Jurassic ophiolites along the BNS which were thrust southwards onto the Lhasa block (Girardeau et al., 1998). It has probably changed partly into a rightlateral strike-slip zone at least near the surface although its exact surface trace is not well defined.

\section{Additional seismological data from local earthquakes}

The various travel time branches from the shotpoints provide a strong challenge for earthquake investigations with their signal frequencies generally lower than those from shot-points. About 12 earthquakes from the Tibetan plateau were inspected and 8 of them were considered adequate for a first interpretation, lying roughly in the southern or northern prolongation of the profile. Their location is from the Epicentral Catalogue of the US Geological Survey. In Table 1, coordinates, possible location errors and magnitudes are listed; the epicenters of the earthquakes were marked in Fig. 1 with stars.

It is well known that effects of mis-locations may cause errors in picking arrivals and plotting travel time diagrams. While the hypocenters are all shallow 
Table 1

Earthquakes around INDEPTH III

\begin{tabular}{llccll}
\hline Event & $\begin{array}{l}\text { Direction } \\
\text { to line }\end{array}$ & & $\varphi$ & $\begin{array}{l}\text { Estim. poss. } \\
\text { mis-location }\end{array}$ & $M$ \\
\hline New 6 & N & 88.60 & 35.27 & $<5 \mathrm{~km}$ & 4.7 \\
New 5 & NNW & 88.84 & 35.25 & $<30 \mathrm{~km}$ & 4.4 \\
$3-24$ & NNW & 87.57 & 34.96 & $<5 \mathrm{~km}$ & 4.4 \\
New 8 & WNW & 86.79 & 34.09 & $<15 \mathrm{~km}$ & 3.8 \\
Various $1-4$ & INLINE & $\sim 89$ & $\sim 32$ & $<3 \mathrm{~km}$ & $?$ \\
$3-56$ & S & 90.98 & 27.56 & $?$ & 5.2 \\
$3-32$ & SW & 87.73 & 28.01 & $?$ & 5.2 \\
$3-11$ & W & 88.17 & 30.13 & $<5 \mathrm{~km}$ & 5.7 \\
New 7 & E & 90.93 & 30.56 & $<5 \mathrm{~km}$ & 4.4 \\
\hline Pam & & & & &
\end{tabular}

Parameters of earthquakes around INDEPTH III, used for interpretation.

and cannot cause serious deviations the possible errors in epicenters were calculated by simple geometry: It was found out that even an error of $15 \mathrm{~km}$ would be negligible for all $\mathrm{P}_{\mathrm{n}}$ branches and would change $\mathrm{P}_{\mathrm{g}}$ branches slightly only near the sources. From the parallel branches of the $\mathrm{P}_{\mathrm{g}}$ from adjacent earthquakes, however, we conclude that - at least in the northern sector-

- lateral errors in location can probably be neglected and

- all hypocenters seem to be shallow.

After Langin et al., 2003, hypocenters in the north are generally less than $20 \mathrm{~km}$, but we conclude from the exact parallelism of the $\mathrm{P}_{\mathrm{g}}$-waves that our four earthquakes in the north are certainly shallower.

In Table 2, crustal and mantle phases are listed. In contrast to signals from the shot-points, all earthquake records show $\mathrm{P}_{\mathrm{n}}$-waves, although they appear weak, short and shingled in the north and show a different beginning. Two sections in the north show indications of $\mathrm{P}_{\mathrm{M}} \mathrm{P}$, apparently near and behind the critical distance (see below for a detailed discussion).

As a first example, we take the shallow $M=4.4$ earthquake New 7, situated about $70 \mathrm{~km}$ east of the southern end of INDEPTH III. It was recorded with only $20 \mathrm{samples} / \mathrm{s}$, and except for an anti-alias filter no further filter was used. Fig. 5 shows the record section of the vertical components. The section contains much lower frequency $(f)$ than any of the sections from the shot-points. The time jump visible for all southern shot-points near the BNS system shows up clearly in this section, too, although with smaller amplitudes. At larger offsets a velocity of 6.9 $\mathrm{km} / \mathrm{s}$ (lower crust) is observed, the highest crustal velocity recorded from any earthquake along INDEPTH III. It is followed by a clear low $\mathrm{f}$ mantle velocity of $>8.1 \mathrm{~km} / \mathrm{s}$ at distances of $>295 \mathrm{~km}$, and at a travel time of $\sim 52 \mathrm{~s}$. It is a straight and long $\mathrm{P}_{\mathrm{n}}$ branch, similar to record sections from other southern earthquakes. Signs of $\mathrm{P}_{\mathrm{M}} \mathrm{P}$ signals slightly beyond the

Table 2

$\mathrm{P}$-velocities of earthquakes used

\begin{tabular}{|c|c|c|c|c|c|}
\hline \multirow[t]{2}{*}{ Event } & \multirow{2}{*}{$\begin{array}{l}V_{\mathrm{P}} \text { in } \\
\text { upper/lower } \\
\text { crust }(\mathrm{km} / \mathrm{s})\end{array}$} & \multicolumn{3}{|c|}{$P_{n}$ starts at } & \multirow[t]{2}{*}{ Remarks } \\
\hline & & $\begin{array}{l}\text { Distance } \\
(\mathrm{km})\end{array}$ & $\begin{array}{l}\text { Time } \\
\text { (s) }\end{array}$ & $\begin{array}{l}\text { Velocity } \\
(\mathrm{km} / \mathrm{s})\end{array}$ & \\
\hline New 6 & $\mathrm{No} / 6.9$ & 355 & 53 & $7.6-7.7$ & $\begin{array}{l}\text { one short } \mathrm{P}_{\mathrm{n}} \\
\text { branch; } \\
\text { earthquake in } \\
\text { Songpan Terrane, } \\
\text { late } \mathrm{P}_{\mathrm{M}} \mathrm{P} \\
\text { indicated, } \\
\text { no late } \mathrm{P}_{\mathrm{n}}\end{array}$ \\
\hline New 5 & $6.0 / 6.0$ & $\begin{array}{l}300 \\
458 \\
548\end{array}$ & $\begin{array}{l}44 \\
61 \\
82\end{array}$ & $\begin{array}{l}7.7 \\
7.9 \\
7.7\end{array}$ & $\begin{array}{l}\text { first } P_{n} \text { very } \\
\text { short and weak, } \\
\text { other } P_{n} \text { branches } \\
\text { very late, no } \\
\text { crustal vel. }>6.0 \\
\mathrm{~km} / \mathrm{s} \text {, some late } \\
\mathrm{P}_{\mathrm{M}} \mathrm{P} \text { indicated }\end{array}$ \\
\hline $3-24$ & $6.3 / 6.3$ & $\begin{array}{l}275 \\
340\end{array}$ & $\begin{array}{l}44 \\
52\end{array}$ & 7.7 & $\begin{array}{l}\text { very short } \\
\text { branches } \mathrm{P}_{\mathrm{n}} \text {, later } \\
\mathrm{P}_{\mathrm{M}} \mathrm{P} \text { indicated }\end{array}$ \\
\hline New 8 & $6.2 / 6.6$ & $\begin{array}{l}250 \\
400\end{array}$ & $\begin{array}{l}44 \\
64\end{array}$ & $\begin{array}{l}7.7 \\
7.8\end{array}$ & $\begin{array}{l}\text { short branches } \mathrm{P}_{\mathrm{n}} \text {; } \\
\text { delays at BNS }\end{array}$ \\
\hline $\begin{array}{c}\text { Various } \\
1-4\end{array}$ & $\begin{array}{l}5.6,5.8 / \\
6.4 \\
6.5\end{array}$ & - & - & - & $\begin{array}{l}\text { inline, too short } \\
\text { to record mantle } \\
\text { phases }\end{array}$ \\
\hline $3-56$ & $\begin{array}{l}\text { outside } \\
\text { line }\end{array}$ & $<350$ & $<57$ & $8.0-8.2$ & $\begin{array}{l}\text { only one } \mathrm{P}_{\mathrm{n},} \\
\text { smooth delays } \\
\text { around BNS }\end{array}$ \\
\hline $3-32$ & $\begin{array}{l}\text { outside } \\
\text { line }\end{array}$ & $<350$ & $<55$ & 8.0 & $\begin{array}{l}\text { only one } \mathrm{P}_{\mathrm{n}} \text {, } \\
\text { smooth delays } \\
\text { around BNS }\end{array}$ \\
\hline $3-11$ & $6.3 / 6.3$ & 360 & 55 & 8.0 & $\begin{array}{l}\text { perpendicular to } \\
\text { southern part } \\
\text { of line }\end{array}$ \\
\hline New 7 & $6.3 / 6.9$ & 295 & 52 & 8.1 & $\begin{array}{l}\text { large delays at } \\
\text { BNS, very low f., } \\
\text { high vel. in lower } \\
\text { crust }\end{array}$ \\
\hline
\end{tabular}

P-velocities in crust and mantle.

Please note that all northern earthquakes with shingling $\mathrm{P}_{\mathrm{n}}$ have strong crustal branches at later travel times. 


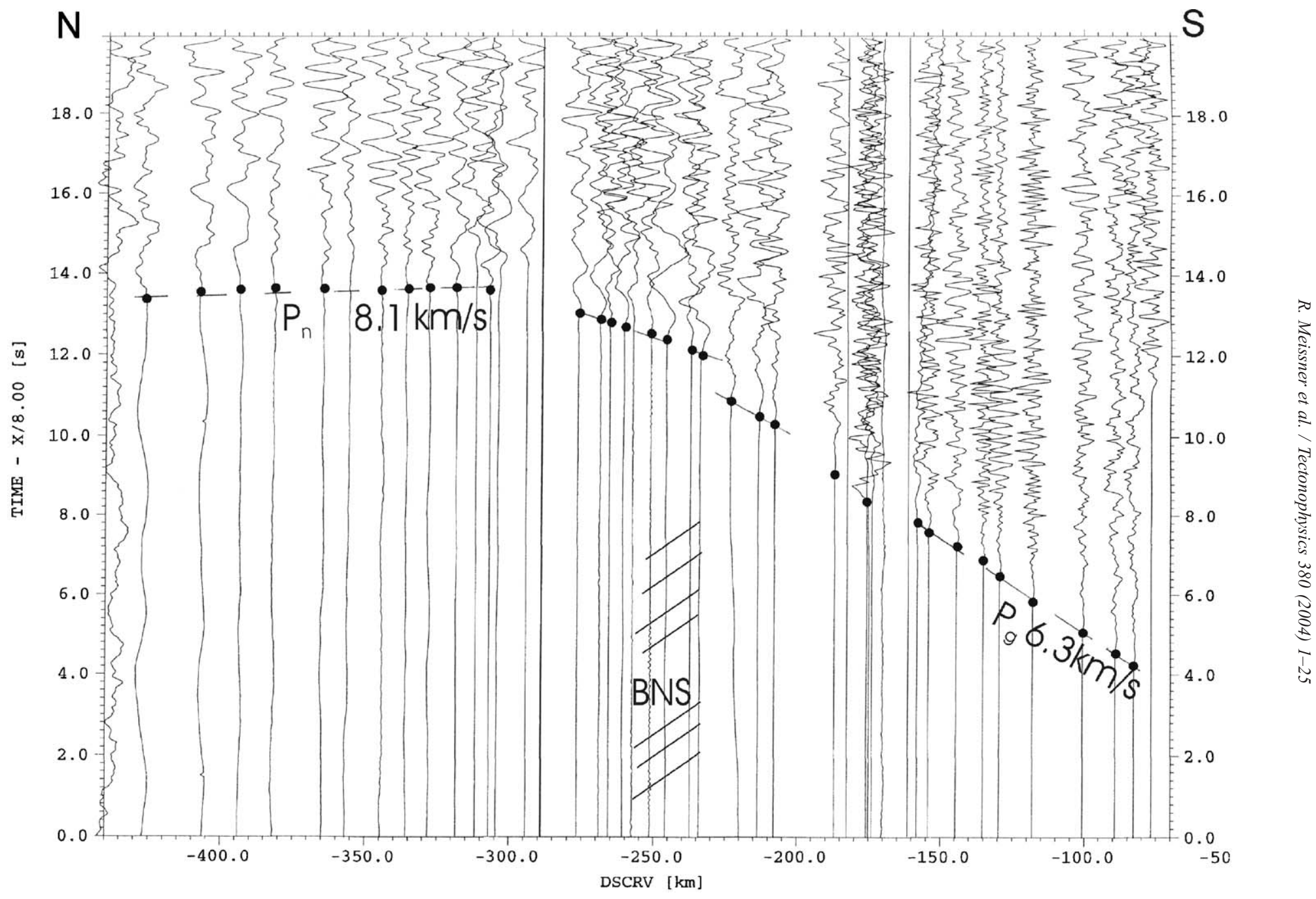

Fig. 5. Record section from the southern earthquake "New 7" (vertical component). Along $x$-axis: distance from the earthquake epicenter in kilometers. Only anti-alias filter applied; BNS and P-phases indicated. 


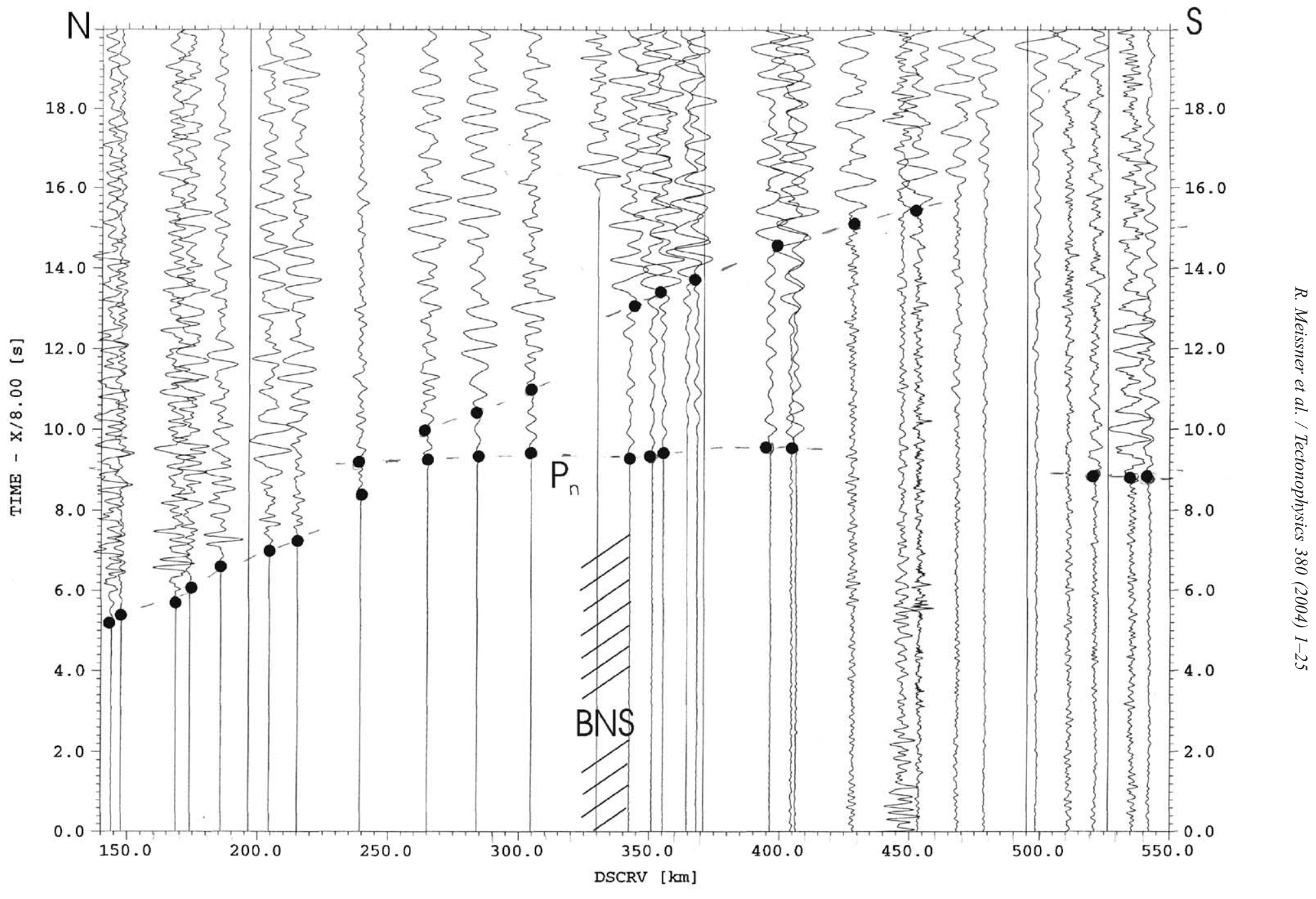

Fig. 6. Record section from the northern earthquake 3-24 (vertical component). Distance from earthquake epicenter (in km); band-pass filter 2-8 Hz; location of BNS indicated. 


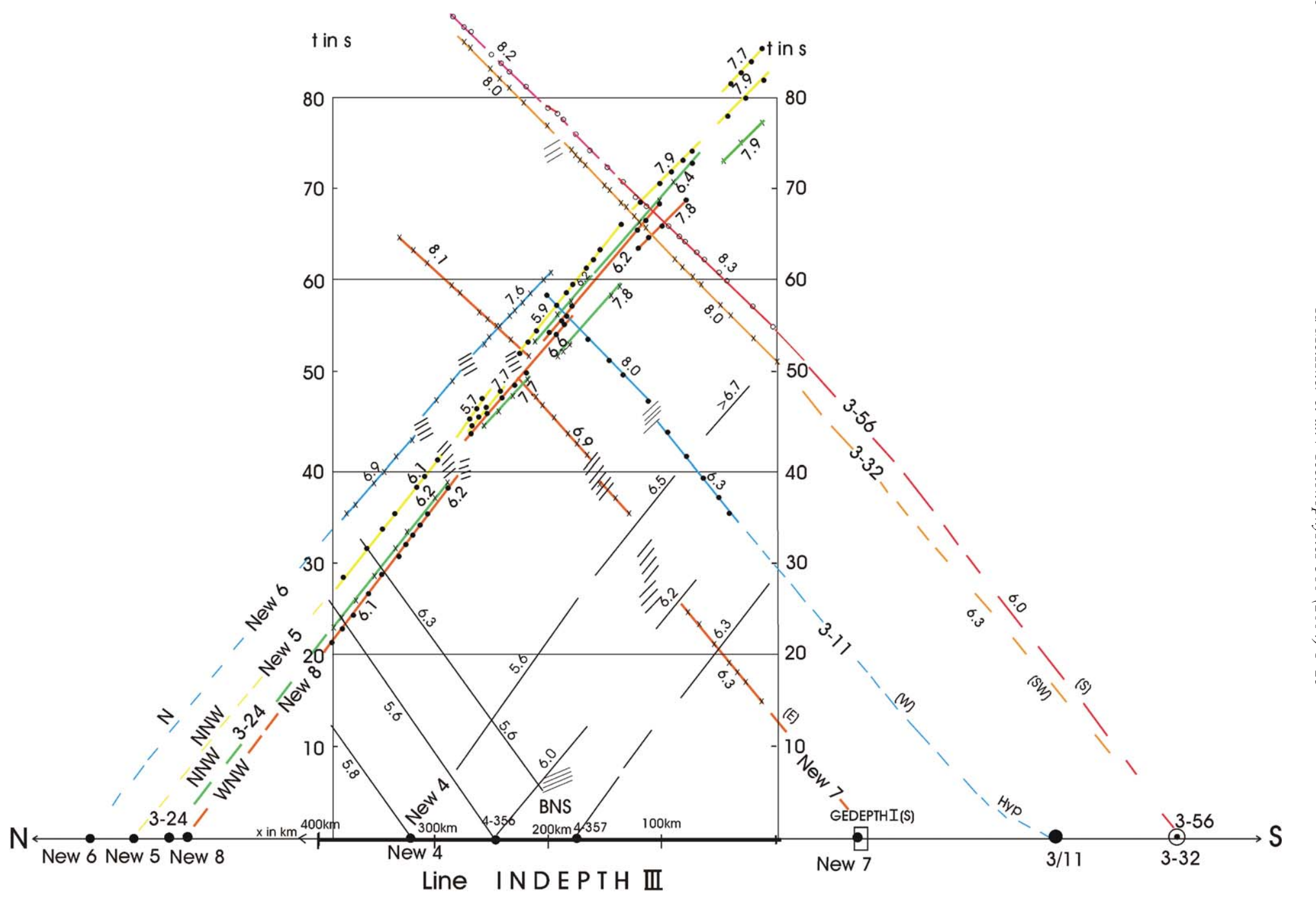

Fig. 7. Unreduced travel times of eight shallow earthquakes in the neighborhood of INDEPTH III (location in Fig. 1). Epicenters of the earthquakes on the $x$-axis, $x$ in kilometers with the INDEPTH profile in the center; fat numbers along travel-time branches: the earthquakes; small numbers: apparent velocities in kilometers per second; interruptions of travel-time branches marked by dashed lines. 
critical angle are indicated in some sections, but they are too weak to try a correlation. It is interesting to note that the two horizontal components of the seismometers recorded clear crustal S-wave arrivals from earthquake New 7, also showing a large jump near the BNS. At larger distances $(>300 \mathrm{~km})$ the horizontal components of New 7 show arrivals with a velocity of $\sim 4.6 \mathrm{~km} / \mathrm{s}$, probably Sn-waves.

An example from the northern earthquakes is shown in Fig. 6. It is the shallow $M=4.4$ earthquake $3-24$, filtered with $2-8 \mathrm{~Hz}$ and situated about $130 \mathrm{~km}$ north of the line. No crustal phases show any velocities higher than $6.3 \mathrm{~km} / \mathrm{s}$. A first short and weak $\mathrm{P}_{\mathrm{n}}$-branch starts at about $250-\mathrm{km}$ distance and a reduced travel-time of $9 \mathrm{~s}$. A second $\mathrm{P}_{\mathrm{n}}$-branch starts at about $350 \mathrm{~km}$ Both $\mathrm{P}_{\mathrm{n}}$-waves have apparent velocities of only 7.7-7.8 km/s. Various indications of $\mathrm{P}_{\mathrm{M}} \mathrm{P}$ are present, apparently matching the $\mathrm{P}_{\mathrm{n}}$-branches, but an exact correlation could not be carried out. Similar observations, i.e., short and shingled $\mathrm{P}_{\mathrm{n}}$-branches with velocities below $8 \mathrm{~km} / \mathrm{s}$, followed by strong and long crustal phases, occur at all three northern earthquakes in the Changtang Block. Earthquake New 5 does not show any crustal velocity higher than $6.1 \mathrm{~km} / \mathrm{s}$ and crustal velocities from the other earthquakes never reach values higher than $6.4 \mathrm{~km} / \mathrm{s}$ (including the "lower" crust). We remember that crustal phases from the northern shot-points (Fig. 3) also showed such very low P-velocities from normal and reverse shooting.

The shallow $M=3.8$ earthquake New 8 with nearly the same northerly distance as earthquake 3-24 but different propagation paths shows similar crustal and mantle phases and similar-but not identical-travel times, often really intermingling with each other as seen in the unreduced and overlapping travel time diagram of the eight earthquakes used (Fig. 7). It mainly shows $\mathrm{P}_{\mathrm{g}^{-}}$and $\mathrm{P}_{\mathrm{n}^{-}}$ phases. Velocities typical for the lower crust (6.5$7.2 \mathrm{~km} / \mathrm{s}$ ) were only detected at three records (New $6,7,8)$, while the remaining four records show crustal velocities around $6-6.3 \mathrm{~km} / \mathrm{s}$. Large parts of the lower crust have much lower velocities than usual. The lack of any clear $\mathrm{P}_{\mathrm{M}} \mathrm{P}$ phases and the appearance of various short and weak $\mathrm{P}_{\mathrm{n}}$-travel time branches are indications of a complex and unusual structure of the crust and its bottom. This kind of scatter is most evident for the signals from the three earthquakes in the Changtang Block in the north. These observations support the idea that here the crust is certainly unusual and the transition zone at the Moho appears highly complex. The first $\mathrm{P}_{\mathrm{n}}$ branch is possibly only a thin layer within the transition zone. The low velocities in the whole northern crust will be discussed again in the Discussion section.

\section{Heterogeneity, layering and Moho-transition}

We plotted the $\mathrm{P}_{\mathrm{n}}$-phases symmetrically in a preliminary depth profile and note that all northern earthquakes show $\mathrm{P}_{\mathrm{n}}$-refractors in the Changtang Block, and all southern earthquakes have $\mathrm{P}_{\mathrm{n}}$-refractors in the Lhasa Block (Fig. 8). There is no overlapping of the $\mathrm{P}_{\mathrm{n}}$-travel times. The pronounced scatter of mantle phases and their unusually low velocities in the Changtang Block is certainly larger that in most other profiles. A large contribution to the complexity of the lower crust might be effected by a transition from gabbro to eclogite facies, as generally supposed for a crustal depth of more than $60 \mathrm{~km}$ and moderate temperatures (Furlong and Fountain, 1986; Le Pichon et al., 1997).

Since the first experimental investigation of the gabbro-eclogite transformation (Ringwood and Green, 1966; Green and Ringwood, 1967), it has been argued that the crust-mantle transition in areas of thickened crust may be a velocity gradient zone. Especially Ito and Kennedy (1971) and Furlong and Fountain (1986) studied the petrological and geophysical consequences. They developed models with various velocity-gradient zones at the base of the crust and studied the influence of temperature, as estimated from surface heat flow. As a consequence, there would be no first-order boundary at the base of the crust, no (high $f$ ) reflections and no energy below the critical angle (i.e., no near-vertical reflections).

It is well known from theoretical and experimental evidence that in case of a gradient zone a diving wave is generated (if the seismic wavelength $\lambda$ is small compared to the thickness $\mathrm{d}$ of the gradient zone). A wave in a strong-gradient zone is also called a retrograde diving wave, and its hyperbolic travel time 


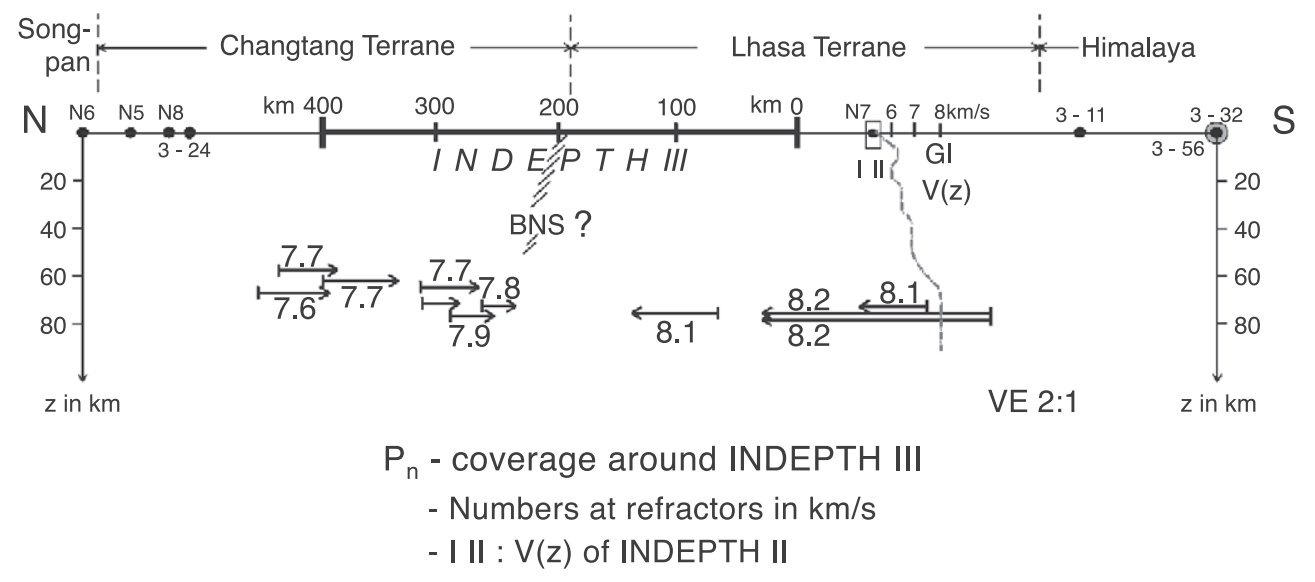

Fig. 8. Location of $\mathrm{P}_{\mathrm{n}}$-phases from the earthquakes; coverage assumed to be at the center between earthquakes and receivers. Velocity-depth relationship $V(z)$ taken from GEDEPTH I (GI). Large numbers along $\mathrm{P}_{\mathrm{n}}$-phases: velocities in kilometers per second.

curve is very similar to that of a real wide-angle reflection (Meissner, 1996). Such wide-angle reflections from the Moho, on the other hand, do have at least some energy below the critical angle, showing apparent velocities larger than $8 \mathrm{~km} / \mathrm{s}$. In general, the expression $\mathrm{P}_{\mathrm{M}} \mathrm{P}$ is used for both kinds of waves, real reflections and diving waves.

Looking again at the $\mathrm{P}_{\mathrm{M}} \mathrm{P}$ phases from the three shot-points 3,4 and 10, we do not observe any energy below the critical angle. On the other hand (at least for the southern shots, e.g., shot 3), the modeling of $\mathrm{P}_{\mathrm{M}} \mathrm{P}$ provides some energy below the critical angle if the Moho is assumed to be a firstorder boundary (Fig. 9 of Zhao et al., 2001). This does not agree with the observations and provides another argument for the Moho being a transition zone, similar to the reasoning of Kola-Ojo and Meissner (2001) from the observations of GEDEPTH I (INDEPTH II).

It should also be mentioned that in practice the phase $P_{n}$ (the refracted Moho event) is also a diving wave (in a small-gradient zone), being prograde. We know that the $\mathrm{P}_{\mathrm{n}}$-wave samples mantle velocities down to a depth of more than $100 \mathrm{~km}$ (Smith and Ekström, 1999). As a consequence, the appearance of $\mathrm{P}_{\mathrm{n}}$ does not depend much on the nature of the crustmantle transition zone.

There are petrophysical and seismological arguments for suspecting a large crust-mantle transition zone in areas with an overthickened crust $(>60 \mathrm{~km}$ depth):

(1) A transition from gabbro to eclogite facies is supposed to start around 50 to $60 \mathrm{~km}$ depth (Sapin and Hirn, 1997), depending on the temperatures (not too high). Such a transition zone probably produces a velocity-gradient zone (Furlong and Fountain, 1986). An additional transition of eclogite into granulite facies is possible contributing to the uplift of the plateau (Le Pichon et al., 1997).

(2) Mantle temperatures in the southern Lhasa Block are rather low because of the intrusion of the (cold) subcrustal Indian lithosphere, possibly carrying with it a certain percentage of lower crust (Kola-Ojo and Meissner, 2001).

(3) Near-vertical Moho reflections along INDEPTH I disappear when the Moho depth exceeds $\sim 60 \mathrm{~km}$ depth (Zhao et al., 1993). Similar observations were made in the Altiplano in the Andes (The ANCORP Working Group, 1999). Here, Moho reflections become more and more diffuse when approaching a depth of $\sim 60 \mathrm{~km}$. Low- $f$ receiver functions do show the Moho in Tibet and in the Andes for depths smaller than $60 \mathrm{~km}$, but provide a suspiciously broad signal for deeper Mohos (Yuan et al., 1997; Yuan, 1999; ANCORP Working Group, 1999). In northern Tibet, the Moho is observed everywhere north of $29^{\circ} \mathrm{N}$ by using the receiver function technique, but it has to be 
remembered that the teleseismic waves have much reduced frequencies (Kind et al., 2002; Yuan et al., 1997).

(4) Also wide-angle reflections along INDEPTH II do not show energy below the critical angle (Makowski and Klemperer, 1999). Near-vertical reflections could not be observed, presumably because of great Moho depth $(>65 \mathrm{~km})$ and a velocity gradient zone (Kola-Ojo and Meissner, 2001).

Remembering these observations, we inspect the new data along INDEPTH III. In the shot records there is no $\mathrm{P}_{\mathrm{n}}$ anywhere, and only three record sections (shot-point 3,4 and 10) show phases of $\mathrm{P}_{\mathrm{M}} \mathrm{P}$. The $\mathrm{P}_{\mathrm{M}} \mathrm{P}$ events start at a distance of more than $200 \mathrm{~km}$ with an apparent velocity of about $8 \mathrm{~km} / \mathrm{s}$; hence, they are presumably diving waves. Fortunately, most earthquakes around INDEPTH III with their rather low frequencies all produce $\mathrm{P}_{\mathrm{n}}$-waves, but no obvious $\mathrm{P}_{\mathrm{M}} \mathrm{P}$ or $\mathrm{S}_{\mathrm{n}}$ and no $\mathrm{S}_{\mathrm{M}} \mathrm{S}$ (details in Tables 1 and 2). Certainly, the lack of clear $\mathrm{P}_{\mathrm{M}} \mathrm{P}$ from the earthquakes and $P_{n}$ from the shots, and only sporadic appearance of $\mathrm{P}_{\mathrm{M}} \mathrm{P}$, indicates an unusually complex crust-mantle boundary. The discrepancies between shots and earthquakes must be related to their respective energy, frequency content and source depth. A thick and complex velocity gradient zone, possibly also involving some layering, such as is observed in the Changtang Block, seems to provide a possible explanation for the unusual behavior of the $\mathrm{P}_{\mathrm{M}} \mathrm{P}$ phases.

We have attempted to put constraints on the thickness of the transition zone by calculating synthetic seismograms with the 1D-reflectivity method (Müller, 1985). The model has been chosen to be close to the lateral average of the model presented in Zhao et al. (2001) in order to facilitate direct comparisons of the synthetic waveforms with the data (Fig. 9a), but it should be kept in mind that we do not attempt to match the data in their entirety but merely wish to explore the behavior of $\mathrm{P}_{\mathrm{M}} \mathrm{P}$ for different offsets. The source time function was chosen to obtain a frequency content similar to the one observable in the shot records, albeit somewhat broadened in order to obtain a compact waveform. The modeling was restricted to $\mathrm{P}$ waves, in order to avoid contamination by wrappedaround slow $\mathrm{S}$ waves and to ease interpretation. The sharp discontinuity at the Moho was replaced by transition zones of various widths, where velocities were interpolated linearly between lower-crustal and mantle velocities. The record sections for a sharp Moho, a 1-km transition width, and a 4-km transition width in Fig. 9b demonstrate that the replacement of the Moho by a transition zone does affect only the phase in the post-critical area, as expected. However, the amplitude of pre-critical $\mathrm{P}_{\mathrm{M}} \mathrm{P}$ at small offsets is strongly reduced and the waveform broadened, even for a transition width of $1 \mathrm{~km}$; the amount of reduction in amplitude increases with decreasing offsets, i.e., $\mathrm{P}_{\mathrm{M}} \mathrm{P}$ at offsets far from the critical distance (180-200 $\mathrm{km}$ for the synthetic models) is more strongly depressed. Fig. 9c shows that for a transition width of 4 $\mathrm{km}$, no significant pre-critical $\mathrm{P}_{\mathrm{M}} \mathrm{P}$ is present. In none of the shot records, there is even a hint of $\mathrm{P}_{\mathrm{M}} \mathrm{P}$ visible at distances less than $30 \mathrm{~km}$ below the critical distance A detailed consideration of pre-critical $\mathrm{P}_{\mathrm{M}} \mathrm{P}$ amplitudes at about $50 \mathrm{~km}$ less than the critical distance shows that a transition width of $\sim 2 \mathrm{~km}$ is sufficient to depress pre-critical $\mathrm{P}_{\mathrm{M}} \mathrm{P}$ to amplitudes that would render it undetectable above the $\mathrm{P}$ coda, whose amplitude in the shot records is $\sim 3-4$ times less than $\mathrm{P}_{\mathrm{M}} \mathrm{P}$ at the critical distance. This result is not strongly dependent on the crustal structure above the Moho; for example, similar results were obtained with simplified models (not shown here) consisting only of a constant velocity upper and lower crustal layer, a constant velocity mantle, and the transition zone. It has also to be kept in mind that $2 \mathrm{~km}$ is a minimum estimate, larger transition widths up to about $10 \mathrm{~km}$ are also compatible with the data and even likely for Tibet south of the BNS, considering that Moho conversions in low $\mathrm{f}$ receiver functions $(<1 \mathrm{~s}$ period) are also significantly reduced.

The amplitude of post-critical $\mathrm{P}_{\mathrm{M}} \mathrm{P}$ exhibits a much smaller dependence on the transition width, and no pulse broadening occurs. However, there is a small variation of travel time, with earlier arrivals for larger transition widths. The travel time effect becomes more pronounced for larger offsets, and results both from details of the model parameterisation, which yields higher velocities in the lower crust for larger transition widths, and from the fact that the effective turning depth becomes shallower, at least for $\mathrm{P}_{\mathrm{M}} \mathrm{P}$ with an apparent velocity below 7.6 $\mathrm{km} / \mathrm{s}$ (intermediate between crustal and mantle velocities). The travel time variations are comparable to 

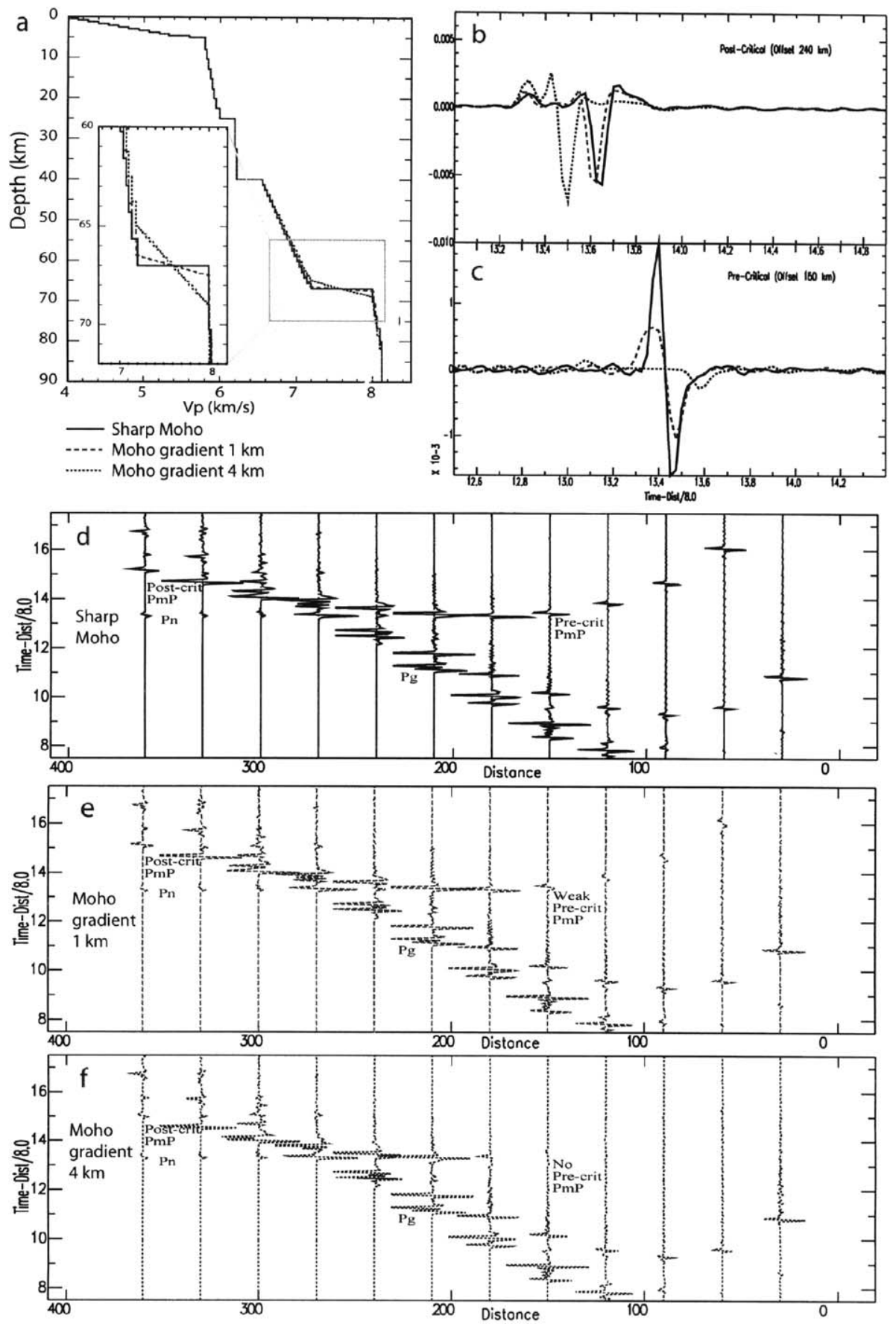

Fig. 9. Reflectivity synthetics for models with different transition width. (a) Velocity-depth models; inset shows detail near Moho. The model with the sharp Moho is close to that of Zhao et al. (2001). (b) Detail of post-critical $\mathrm{P}_{\mathrm{M}} \mathrm{P}$ at an offset of $240 \mathrm{~km}$ for the model with the sharp Moho (solid line), with a transition of $1 \mathrm{~km}$ (dashed) and $4 \mathrm{~km}$ (dotted). (c) Detail of pre-critical $\mathrm{P}_{\mathrm{M}} \mathrm{P}$ at an offset of $150 \mathrm{~km}$ for different transition widths (same symbols as in b). (d-f) Reduced record section for a shot source and models with (d) a sharp Moho and a transition of 1 $\mathrm{km}(\mathrm{e})$ and $4 \mathrm{~km}(\mathrm{f})$. 
the residual RMS for $\mathrm{P}_{\mathrm{M}} \mathrm{P}$ in the Zhao et al. (2001) model. The amplitude variations of post-critical $\mathrm{P}_{\mathrm{M}} \mathrm{P}$ at larger offsets are also related to geometrical effects which in turn are highly dependent on details of the model, in particular the gradient in the lower crust. Specifically, no significant amplitude variations occur in the simplified model described above. Because of this sensitivity to details of the model we refrain from making further use of post-critical $\mathrm{P}_{\mathrm{M}} \mathrm{P}$ amplitudes. Fig. $9 \mathrm{~d}-\mathrm{f}$ shows record sections of the sharp Moho transitions and the two gradient zones.

At first sight, it appears surprising that no obvious $\mathrm{P}_{\mathrm{M}} \mathrm{P}$ is observed in the earthquake records, as their lower frequency content should make them less sensitive to any complexity of the Moho. However, $\mathrm{P}_{\mathrm{M}} \mathrm{P}$ is also very weak in the synthetic data for a buried earthquake source and the preferred model with a transition width of $2 \mathrm{~km}$ (Fig. 10); only very near the critical distance, appreciable amplitudes are obtained (the first arrival after $\mathrm{P}_{\mathrm{n}}$ for offsets larger than $350 \mathrm{~km}$ is a lower crustal refraction). Using the synthetic section as a guide, we can tentatively identify a weak phase just after $\mathrm{P}_{\mathrm{n}}$ for offsets 250 $320 \mathrm{~km}$ in Fig. 6 as $\mathrm{P}_{\mathrm{M}} \mathrm{P}$. No observation of $\mathrm{P}_{\mathrm{M}} \mathrm{P}$ beyond that distance or pre-critically would be expected based on the synthetics; therefore, no additional structure needs to be invoked to explain at first the surprising behaviour of $\mathrm{P}_{\mathrm{M}} \mathrm{P}$ for earthquake sources. We carried out further synthetic experiments to explore the effect of variations of the model and different source parameters. The lack of $\mathrm{P}_{\mathrm{M}} \mathrm{P}$ for large offsets is related only to the depth of the source and the geometry of the model, i.e., it occurs for different focal mechanisms, with or without the gradient zone, and irrespective of the exact frequency content of the source wavelet. The presence of late, large but scattered $\mathrm{P}_{\mathrm{M}} \mathrm{P}$-like amplitudes on earthquakes New 6, New 7 and 3-24, much beyond the critical distance, can be interpreted as a sign for the complexity of the Moho transition and possibly indicate that at least these earthquakes are shallow. From the parallel $\mathrm{P}_{\mathrm{g}}$-branches of the northern earthquakes, we have to conclude that all earthquakes in the Changtang Block are also shallow.

\section{Attenuation, anisotropy and temperature}

As most of the path of $\mathrm{P}_{\mathrm{n}}$ for the shot records is within the 'No-S $\mathrm{S}_{\mathrm{n}}$-zone' previously mapped (Barazangi and $\mathrm{Ni}, 1982$; McNamara et al., 1995), one can speculate that the absence of $\mathrm{P}_{\mathrm{n}}$ on the INDEPTH III shot records is related to the absence of $\mathrm{S}_{\mathrm{n}}$ propagation in the northern part of the INDEPTH III array. By introducing unusually strong attenuation into the sub-Moho layers of the synthetic models, we found that a P-wave quality factor $Q_{\mathrm{P}}$ of $\sim 180-$ 340 (corresponding to $Q_{\mu} \sim 80-150$ ) could explain the absence of high frequency $\mathrm{P}_{\mathrm{n}}$, while leaving the lower-frequency $\mathrm{P}_{\mathrm{n}}$ phase from the earthquakes strong

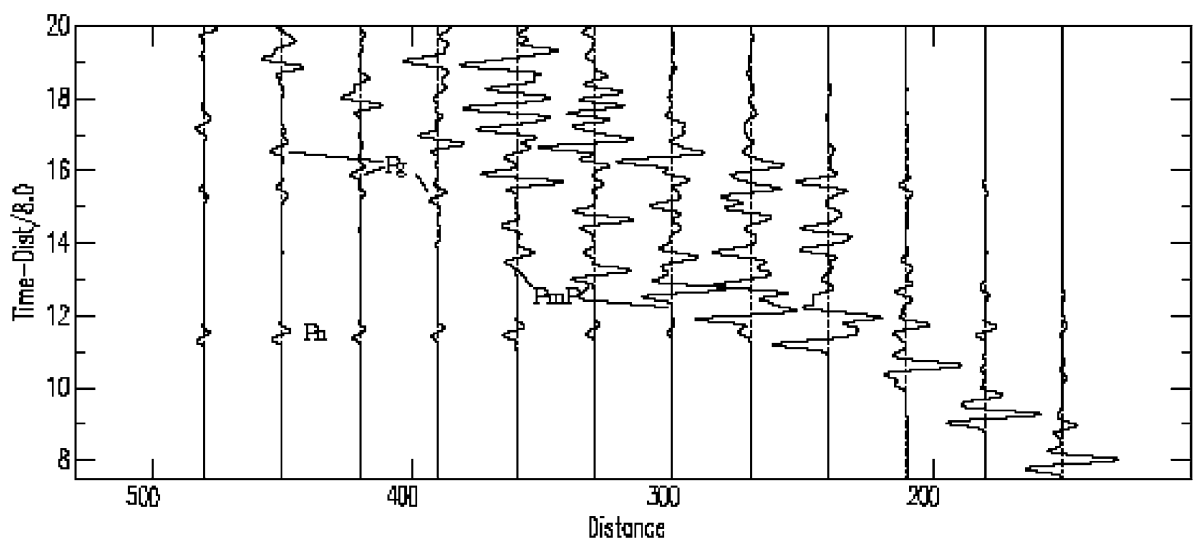

Fig. 10. Reflectivity record section for a buried earthquake source (15 km depth) and the model with a transition width of $2 \mathrm{~km}$. Reduced traveltime and distance refer to the hypocenter (outside figure). 
enough to be detected over the ranges considered in this paper. At the same time, $S_{n}$ would be suppressed, too. However, previous modeling has shown (Crotwell et al., 1995) that it is not possible by attenuation alone to wipe out $S_{n}$ within the attenuating zone but let $\mathrm{P}_{\mathrm{n}}$ from local earthquakes propagate across the whole plateau. Additional model studies show that it is likely that the observations on the efficiency of mantle phases in Tibet (no efficient propagation of $S_{n}$ and very high frequency $\mathrm{P}_{\mathrm{n}}$; efficient propagation of intermediate $P_{n}$ from earthquakes) can only be explained by both increased attenuation and a difference in the velocity gradients. Both effects could result from partial melting of the mantle.

Basaltic volcanism of different age but continuing until the most recent past (less than $5 \mathrm{Ma}$ ) is known to have occurred in northern Tibet (Yin and Harrison, 2000). The depletion due to partial melting would result in a gradual increase in olivine content relative to orthopyroxene and clinopyroxene with depth, which in turn would cause the P velocity gradient to be steeper than the S velocity gradient (Fuchs, 1983).

In Fig. 11, we have plotted the average velocitydepth structure with a crust-mantle transition zone and Fig. 12 shows the velocity model of INDEPTH III including the data from GEDEPTH I (Kola-Ojo and Meissner, 2001). The sudden appearance of strong SKS anisotropy south of the BNS (Huang et al., 2000) can only be explained by a considerable contribution from the crust, while the strong amplitude of the anisotropy suggests a large contribution from the mantle (Fig. 13). The whole Changtang Block seems to be horizontally anisotropic, with the strongest anisotropy (up to $2.5 \mathrm{~s}$ delay time) concentrated near the fault bounding shear zones; the fast directions there oriented close to east-west, whereas in the interior of the block fast directions vary from EW to NE (McNamara et al., 1994; Herquel et al., 1995; Huang et al., 2000). The beginning of strong shear wave splitting anisotropy about $25 \mathrm{~km}$ south of the BNS indicates that parts of the subducting Indian subcrustal lithosphere (Tilmann et al., 2003) delaminates also laterally as suggested by Kola-Ojo and Meissner (2001).

The supposed lattice preferred orientation (LPO) seems to be caused by an extrusion or escape tectonics of the whole lithosphere to the east, as already suggested by Molnar and Tapponier (1975), Tappon- nier (1990), Burke and Sengör (1986), Avouac and Tapponnier (1993), Hirn et al. (1995) and Park and Levin (2002). East of Tibet, there is an especially weak lithosphere and the strong north-south compression in Tibet expels the lithosphere eastward. The sudden appearance and the large amount of anisotropy suggests that considerable parts (the warm and weak layers) of the whole lithosphere contribute to the escape process in the Changtang block.

Unfortunately, the INDEPTH III profile is nearly perpendicular to the fast axis of anisotropy and will not display the high values of $P_{n}$, suspected in the west-east direction. A south-north direction (perpendicular to the fast axes) should show only slightly lower velocities than for isotropic material (Kern et al., 1996; Vinnik et al., 1992). The rays through the Changtang block indeed show lower $\mathrm{P}_{\mathrm{n}}$-velocities: between 7.6 and $7.9 \mathrm{~km} / \mathrm{s}$, compared to $8.0-8.2$ in the southern part of the line and $8.2-8.3 \mathrm{~km} / \mathrm{s}$ in the southern Lhasa Block (Beghoul et al., 1993). Possibly, the low velocities in the north are an indication for anisotropy, but other causes like higher temperatures and hence attenuation in the north are additional (or alternative) explanations. Kind et al. (2002) really find a gradual lowering of the Moho from about $80 \mathrm{~km}$ beneath the Yarlung Tsangpo Suture to $\sim 65 \mathrm{~km}$ under northern Tibet from receiver function studies, but they do not find a significant change in crustal thickness north of the BNS. That means that the low $\mathrm{P}_{\mathrm{n}}$-velocities in the Changtang Block are true and not effected by a dipping Moho. There was also no rise of the Moho found by the dispersion studies of Rapine et al. (2003), but their data would possibly not be able to resolve a small step $(<5 \mathrm{~km})$ in the Moho.

Higher temperatures in the mantle of northern Tibet have long been suggested, mainly based on S-wave attenuation (Beghoul et al., 1993) and magmatism (Tapponier et al., 2001). Also, in the paper of Kind et al. (2002), a $300{ }^{\circ} \mathrm{C}$ hotter lithosphere in the north is estimated from receiver function studies. Rapine et al. (2003) find a low lower-crustal S-wave velocities and the absence of an $\mathrm{S}$ velocity gradient in the mantle beneath northern Tibet from dispersion studies. McNamara et al. (1995), studying $\mathrm{S}_{\mathrm{n}}$ regionally, map a large elliptically formed attenuation area in central Tibet, mainly in the Changtang Block. Quaternary volcanism and our unusually low P-velocities in the lower crust and upper mantle from 

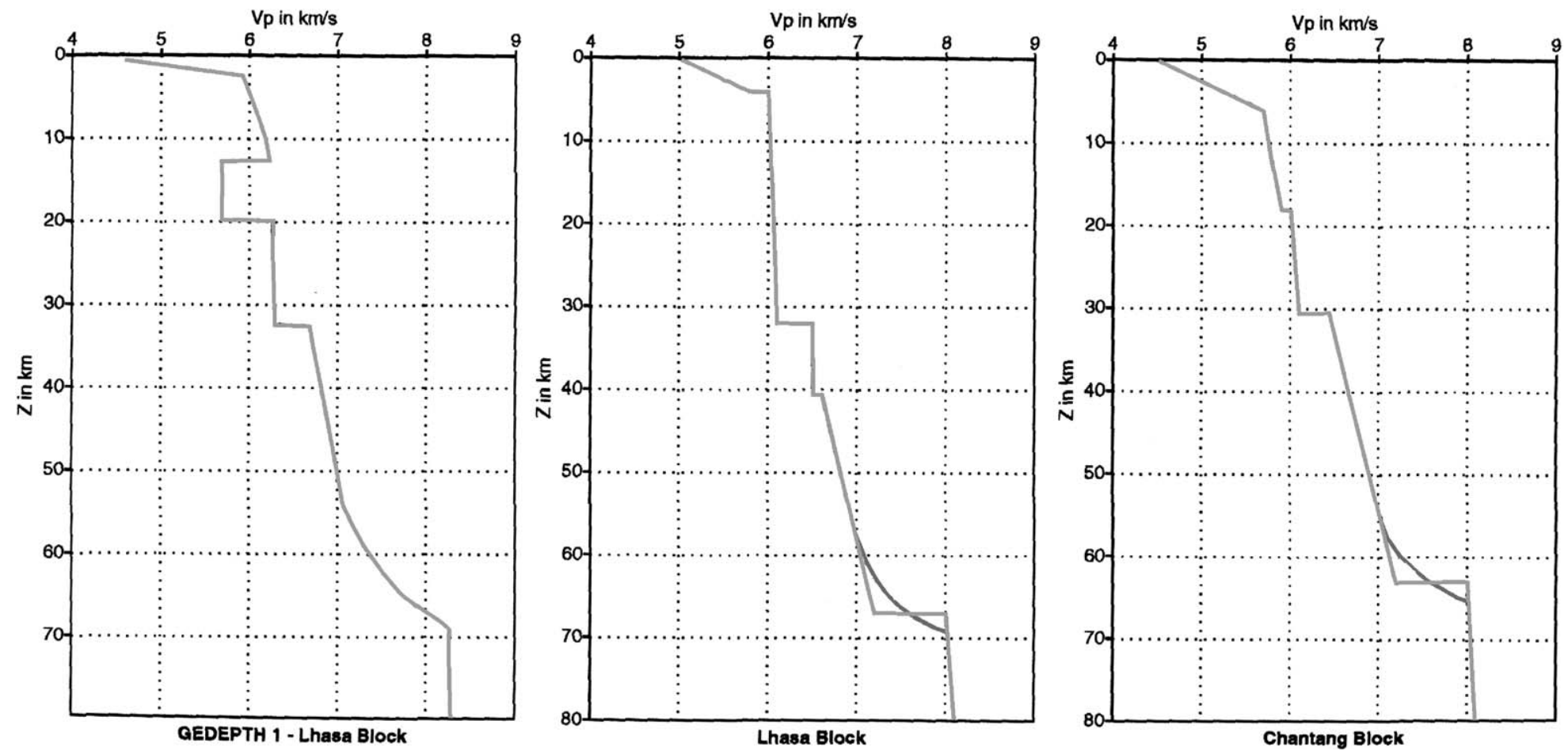

Fig. 11. Velocity-depth $V(z)$ structure in central and southern Tibet, including a crust-mantle transition zone. The transition — compared to a first-order boundary in the two right figures - is shown schematically. 
| N D E P T H |||

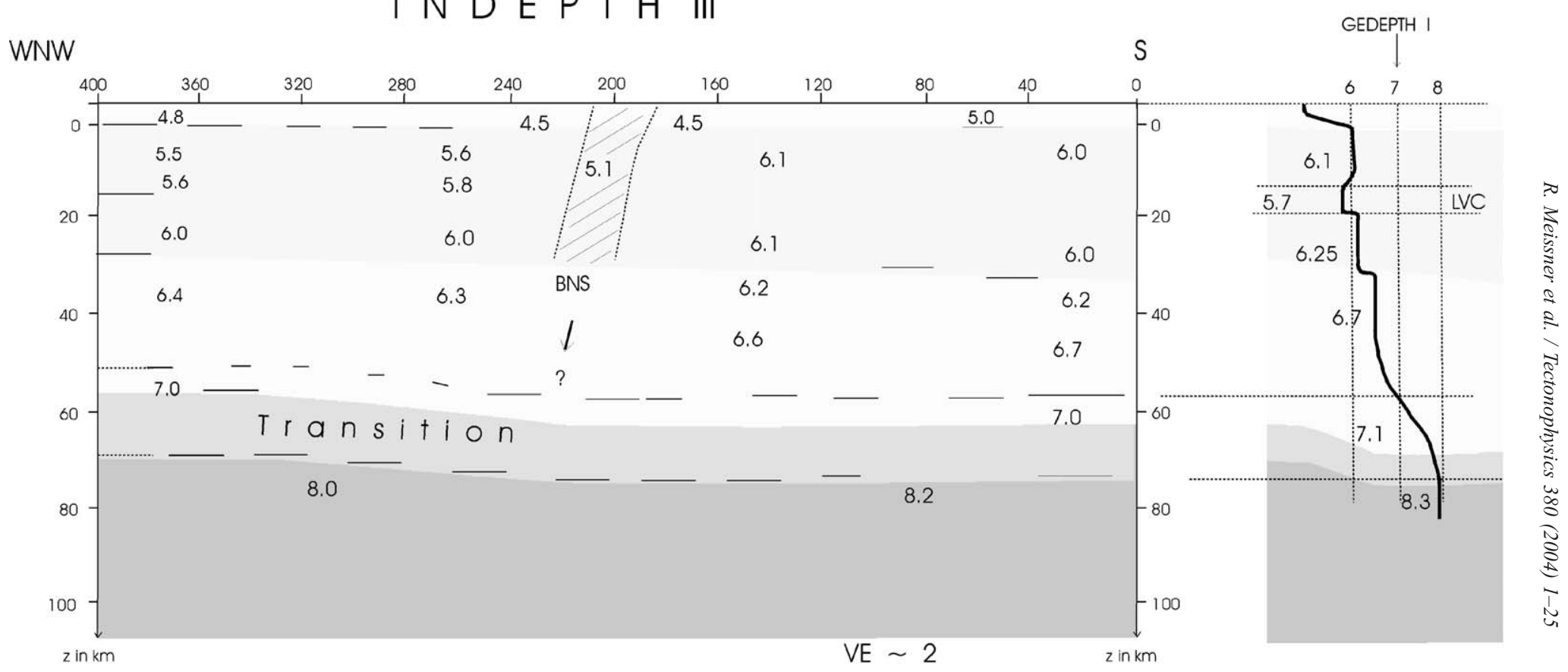

Velocity - Depth Structure along I NDEPTH III and GEDEPTH I

Fig. 12. The INDEPTH III $V(z)$ model, together with that of GEDEPTH I (INDEPTH II). Vertical exaggeration is 2. 


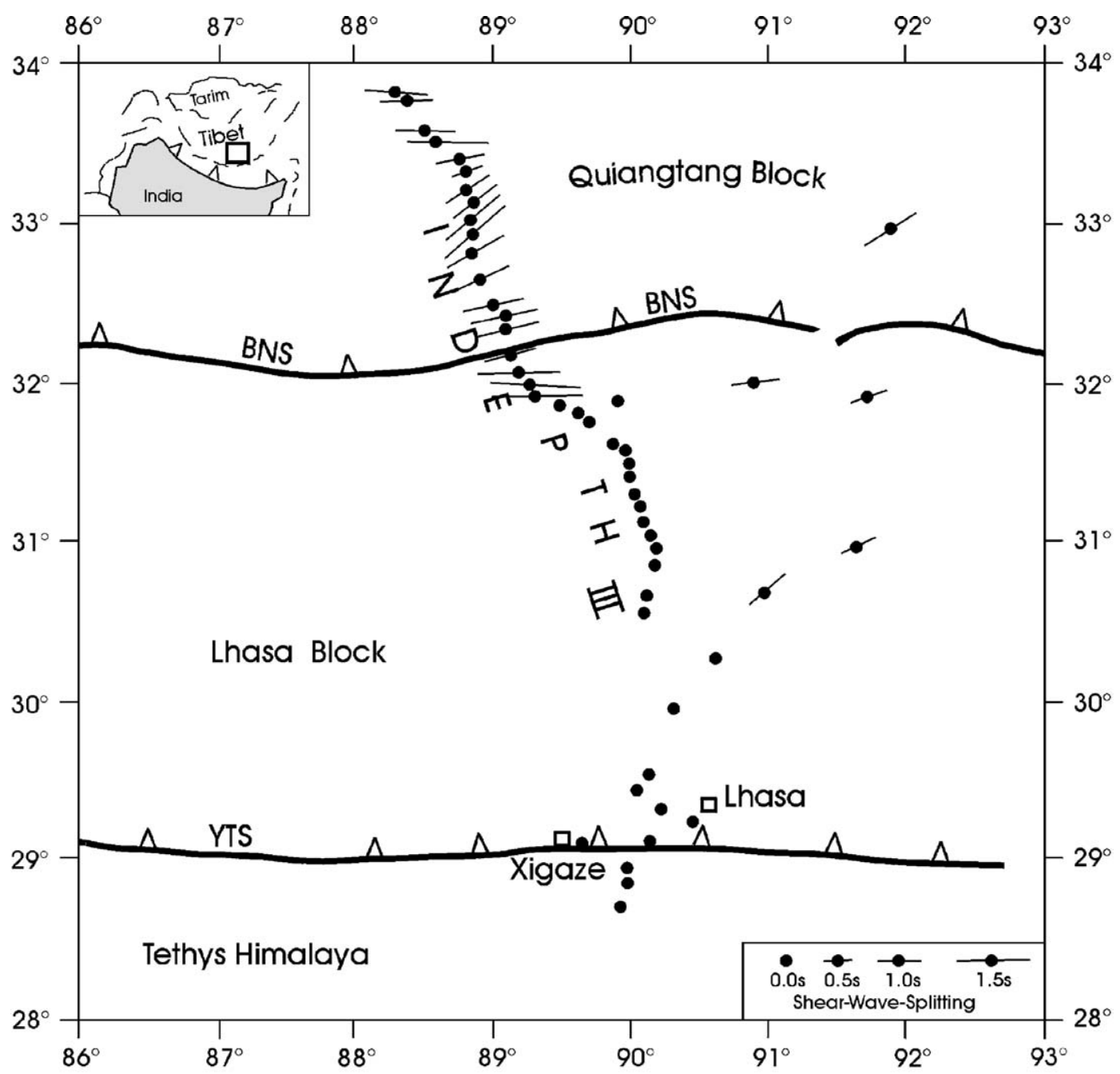

Fig. 13. S-anisotropy along INDEPTH III and some selected older data in southern Tibet, after Huang et al. (2000).

wide-angle and refraction studies, and $\mathrm{P}_{\mathrm{n}}$ tomography (McNamara et al., 1997; Haines et al., 2003) fit perfectly into the concept of a hot, attenuating and weak, possibly anisotropic and easterly escaping, lithosphere.

\section{Discussion}

We discuss first the correlation of seismic arrivals around the BNS system. We have interpreted a large sudden travel time delay (the "jump") in the shotpoint records and in the nearby earthquake New 7 as indicating a near vertical fault zone. The interpretation goes beyond that of Zhao et al. (2001) and Haines et al. (2003) who both find a very low velocity area around the BNS; it is apparently identical to the mapped low velocity zone around the BNS system marked by Haines et al. (2003) and Zhao et al. (2001) based on an extensive ray analysis of shot-point signals. Our jump occurs only in the $\mathrm{P}_{\mathrm{g}}$ arrivals and is nearly absent in $\mathrm{P}_{\mathrm{n}}$, indicating a disturbance of the upper crust down to about 35 $\mathrm{km}$, the greatest depth of the $\mathrm{P}_{\mathrm{g}}$ waves. On the other hand, Tilmann et al., (2002) find a high-velocity body in the lithosphere below about 200-km depth. 
One might speculate that this near-vertical structure represents the subducting subcrustal Indian lithosphere (SCIL) which may have reached this distance (Kola-Ojo and Meissner, 2001), but a connection to the low velocity zone near the BNS system at the surface seems highly speculative.

We next discuss the strange behavior of signals from the shots and from the earthquakes: only postcritical $\mathrm{P}_{\mathrm{M}} \mathrm{P}$ and no $\mathrm{P}_{\mathrm{n}}$ from the shots; clear $\mathrm{P}_{\mathrm{n}}$ from the earthquakes, although short, weak and shingled in the Changtang Block, and only indications of $\mathrm{P}_{\mathrm{M}} \mathrm{P}$, observable close to and beyond the critical distance. Such observations have occasionally been made in other regions (Blümling and Prodehl, 1983). Mostly, frequency-dependent signals together with thin layers have been suggested to explain these phenomena. For Moho-events from deep structures, a large transition zone has been suggested by Mooney and Prodehl (1984 and references therein) and Kola-Ojo and Meissner (2001).

Many researchers have investigated the effects of the large and continuous convergence rate between India and Asia which started $\sim 70 \mathrm{Ma}$ ago (Tapponnier, 1981, 1990; Yin and Harrison, 2000; Kola-Ojo and Meissner, 2001; Galvé et al., 2002). Most of these observations, however, refer to the upper (rigid) part of the crust. They are supported by focal plane solutions of shallow earthquakes which show north-south compression in the Himalaya and southern Tibet, but east-west extensional solutions in central and northern Tibet (Barazangi, 1989), which is generally related to a tectonic escape to the east (Burke and Sengör, 1986). Also new GPS measurements through the central Changtang Block (Wang et al., 2001) confirm escape rates of $1.0-2.0 \mathrm{~cm} /$ year, showing a maximum at the limiting fault zones, the Kunlun in the north and the BNS in the south. According to Dewey et al. (1988) and Ratschbacher (1996), one third of the Indian-Asia conversion is accommodated by lateral extrusion. It is suspected that the upper (rigid) part of the crust moves on the shoulder of the hot and weak lower crust because many observations of seismology and heat flow studies indicate a warm and weak lower crust, apparently hot and wet in the south, hot and dry in the north (Henry et al., 1997; Meissner and Mooney, 1998; Kola-Ojo and Meissner, 2001; Kind et al., 2002). It should be remembered that a temperature of
$800{ }^{\circ} \mathrm{C}$ does not much weaken the upper mantle, but it is above the solidus of granitic and even gabbroic material (Meissner and Strehlau, 1982), causing a dramatic weakening in a thick crust (e.g., Haines et al., 2003), generating partial melts, possibly partly responsible for the low crustal velocities.

From the rheological point of view, the warm area of central Tibet must have weak layers in the lower crust and also in the upper mantle, leading necessarily to a differential escape under appropriate stress. It has been argued that the rather uniform uplift and high elevation of the Tibetan plateau and the overthickened crust is caused by a general compression of ductile crustal material (Zhao and Morgan, 1985, 1987; Westaway, 1995; Kola-Ojo and Meissner, 2001). This "Hydraulic Pump" model provides a possibility for explaining the uniform thickening of the whole plateau, although an underthrust intrusion from the cold subcrustal Indian lithosphere (SCIL) takes place in the southern part (Beghoul et al., 1993) and might contribute to the uplift. The underthrust model was first suggested by Barazangi and $\mathrm{Ni}$ (1982) and was later confirmed by Beghoul et al. (1993), who measured a rather high (cold) $\mathrm{P}_{\mathrm{n}}$-velocity of more than $8.2 \mathrm{~km} / \mathrm{s}$ (like our data in the Lhasa Block), and calculated a thick SCIL of more than $135 \mathrm{~km}$. This confirms the presence of the Indian mantle below southern Tibet which seems to continue at least up to about the middle of Tibet (Tilmann et al., 2002). This observation suggests at least three different shortening mechanisms:

(1) The upper (rigid) part of the crust is subjected to orogen-and fault-related processes (crustal shortening). There is ample stacking along (lubricated?) faults (Brown et al., 1996; Nelson et al., 1996) and possibly even a "hidden" subduction (Tapponier et al., 2001). The (near-surface) fault in the area of the BNS system that we observe in the overlapping travel time diagrams is only one example of a prominent fault zone, reaching down at least to about $35 \mathrm{~km}$.

(2) The middle and lower parts of the crust experience ductile shortening mechanisms where the main tectonic stress comes from the intruding SCIL from the south. In the Changtang Block, most of the crust shows velocities typical for the upper crust. No 
stratification is observed any more between upper and lower crust. Shot-points and earthquakes provide velocities higher than $6.3 \mathrm{~km} / \mathrm{s}$ only sporadically, and a general mixing of (warm) material has to be assumed, possibly a by-product of escape. At the bottom of the crust, the shingled $P_{n}$ seems to represent thin layers of mantle material being intruded into the lower crust, forming a complex transition zone, probably supported by the escape movement. In the north-east of the Changtang Block, Galvé et al. (2002) observe an apparent "thickening" of the upper crust from fan observations. This "thickening" agrees with our measurements of low velocities in the whole crust of the (western) Changtang Block. Based on $V_{\mathrm{P}} /$ $V_{\mathrm{S}}$ ratio, Vergné et al. (2002) infer a thick felsic crust overlying a relatively thin mafic lower crust in the same area, again grossly consistent with the scenario presented here.
(3) The fate of the intruding SCIL, however, is problematic and several processes are discussed. There is first thermal thinning (Beghoul et al., 1993; Yin and Harrison, 2000), certainly a serious candidate, because no deep earthquakes appear any more in the northern Lhasa or the Changtang Block. Thermal thinning, however, cannot dissolve the whole SCIL, and Yin and Harrison (2000) also suggest a subduction-like delamination near the BNS system and below the Changtang Block. On the other hand, no sign of subduction is observed along INDEPTH III, neither in seismicity nor in the signals from the shots or earthquakes. However, teleseismic tomography shows a steep high-velocity slab in the upper mantle (Tilmann et al., 2002). Vertical (or some lateral) delamination would provide an effective shortening mechanism. The sudden appearance of strong anisotropy slightly south of the BNS system is an important

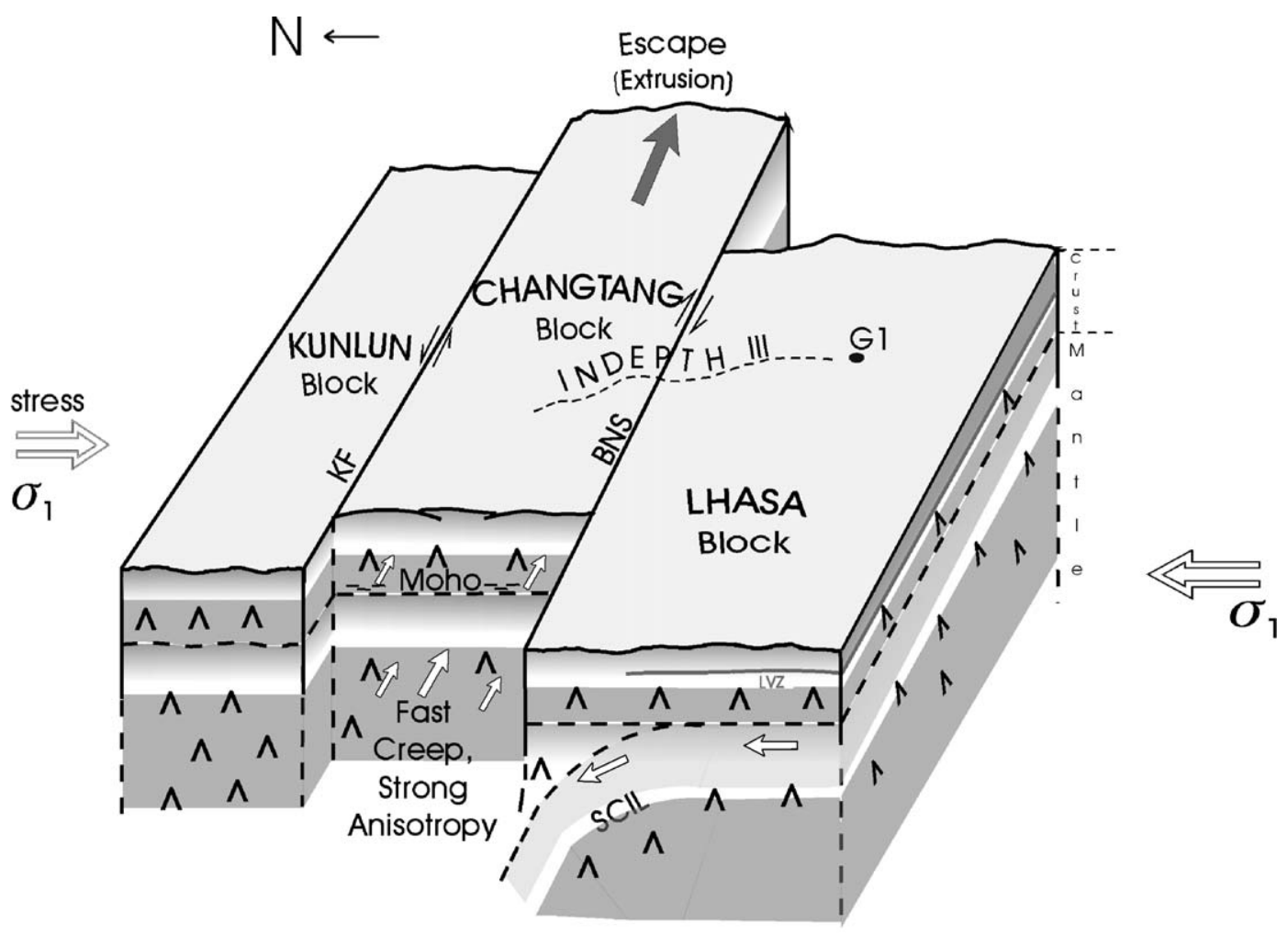

Fig. 14. Conceptual tectonic picture of central Tibet. Different shadings indicate viscosity level; weak layers are in lower crust and below the mantle lid. $\mathrm{KF}=$ Kunlun Fault. SCIL $=$ Subcrustal Indian Lithosphere, subducting (?). GI = GEDEPTH I location. $\sigma_{1}=$ main (compressiv) tectonic stress. 
observation and suggests the beginning of a large and sudden flow (or creep) process in the mantle and crust.

As mentioned, the crust in central Tibet, especially in the Changtang Block, is known to move eastward, from GPS measurements, from tectonic mapping and fault plane solutions. In the north, there is a wellknown left-lateral movement along the Kunlun Fault for the last 40,000 years (Van der Voerd et al., 2002), in the south some right-lateral movement seems to take place in the vicinity of the BNS system. The actual surface displacements along the faults are only $1-1.4$ or $1-2 \mathrm{~cm} /$ year by GPS regionally (Wang et al., 2001). Meissner et al. (2002) estimate an eastward movement of central Tibet around $1.6 \mathrm{~cm} /$ year. This figure compares well with the estimate of Ratschbacher (1996) that one third of the current total convergence of $5 \mathrm{~cm} /$ year between India and Asia is taken up by lateral extrusion. Neither from the shots nor from the earthquakes a low velocity layer in the upper or middle crust was detected, in accordance with the interpretations of Zhao et al. (2001) and Haines et al. (2003).

It seems from the combination of geological mapping, fault plane solutions and anisotropy data that crust and mantle in central Tibet escape to the east. They seem to separate laterally, contributing to the strong west-east anisotropy in the Changtang Block. The movement might start along near-vertical fault zones (like the BNS system and the Kunlun Fault), and at deeper levels along a weak zone of enhanced creep. Part of the SCIL might subduct and delaminate, possibly partly laterally because of the beginning of strong anisotropy slightly south oft he BNS (Huang et al., 2000). At depth, it might mobilize hot asthenospheric material and contribute to warming and uplift (England and Houseman, 1986; Meissner and Mooney, 1998). In Fig. 14, we have tried to combine the suggested pattern of movement, the SCIL partly delaminating downwards, partly laterally.

\section{Conclusions}

From the combination of seismological and shallow geological observations, a number of new struc- tural and tectonic features of central Tibet was revealed.

(1) In the middle of INDEPTH III, the BanggongNuijang Fault system (BNS) is characterized by jumps or delays of travel times from shots and from earthquakes. The BNS seems to reach down from the surface to at least $35-\mathrm{km}$ depth with a steep, probably northerly, dip. No (near horizontal) low velocity layer-like in the southern Lahsa Block-was found along INDEPTH III.

(2) Comparing mantle phases from 11 shots (some $\mathrm{P}_{\mathrm{M}} \mathrm{P}$, no $\mathrm{P}_{\mathrm{n}}$ ) and 8 local earthquakes (always some $\mathrm{P}_{n}$, $\mathrm{P}_{\mathrm{M}} \mathrm{P}$ only observable close to, and beyond, the critical distance) a complex Moho transition is indicated, especially in the Changtang Block. From the absence of subcritical $\mathrm{P}_{\mathrm{M}} \mathrm{P}$ and some unusual $\mathrm{P}_{\mathrm{n}}$-events the Moho transition is suspected to be a velocity gradient zone, in accordance with petrophysical reasoning about a gabbro-eclogite transition. Comparison with reflectivity yield a minimum of $2 \mathrm{~km}$ for the gradient zone which must be very heterogeneous in the Changtang Block and apparently rather smooth in the Lhasa Block.

(3) Based on the observed P-velocities the unusually thick crust in Tibet $(\sim 70 \mathrm{~km})$ is formed in the south by a doubling of the (rigid) upper crust and a doubling of the (ductile) lower crust In the Changtang Block; however, only a doubling of the upper crust or a general mixing of hot crustal material seems to have taken place. P-velocities in lower crustal depths resemble those of the upper crust. This absence of typical lower crust velocities and the appearance of shingled $\mathrm{P}_{\mathrm{n}}$ may be related to the tectonic escape and some indentations of mantle slices plus attenuation and a suspected P-anisotropy with the fast direction west-east (like the S-anisotropy) and a slower component in the south-north direction, i.e., parallel to INDEPTH III. Also, the $\mathrm{P}_{\mathrm{n}}$-velocities in the Changtang Block are lower than normal and the $\mathrm{P}_{\mathrm{n}}$-branches are short and shingled. Our interpretation of travel times is considered to provide the most reliable velocity values available in central Tibet.

(4) The intruding subcrustal Indian lithosphere known to be present in the southern Lhasa Block may have reached the area of the BNS in the middle of Tibet where it might delaminate vertically or even (partly) laterally, as suggested by early beginning of 
S-anisotropy and in accordance with the west-east escape of the Changtang Block.

\section{Acknowledgements}

J. Mechie helped with some technical aspects of the paper and with encouraging discussions. Dr. Yuan and two referees critically read and improved the original manuscript. We acknowledge the support of the Ministry of Land and Resources, China, the National, Natural Science Foundation of China, the US-National Science Foundation, the Deutsche Forschungsgemeinschaft and the GeoForschungszentrum in Potsdam. Instruments were provided by IRISPASSCAL and the Potsdam Instrument Pool. We specially thank the Chinese-US-American-German INDEPTH III field crew for their extremely hard work under very unusual conditions. We appreciate the preliminary determination of the earthquake coordinates by the USGS.

\section{References}

ANCORP Working Group, 1999. Seismic reflection image revealing offset of Andean subduction zone earthquake locations into oceanic mantle. Nature, 341-344.

Argand, E., 1924. La tectonique de 1'Asie. Rep. Sess.-Int. Geol. Congr. 13, 170-372.

Avouac, J., Tapponnier, P., 1993. Kinematic model of active deformation in Central Asia. Geophys. Res. Lett. 20, 895-898.

Barazangi, M., 1989. Continental collision zones: seismotectonics and crustal structure. In: James, D.H. (Ed.), The Encyclopedia of the Solid Earth Geophysics. Van Nostrand-Reinhold, New York, pp. 58-75.

Barazangi, M., Ni, J., 1982. Velocity and propagation characteristics of $P_{n}$ and $S_{n}$ beneath the Himalayan arc and the Tibetan plateau: possible evidence for underthrusting of the Indian continental lithosphere beneath Tibet. Geology 10, 179-185.

Beghoul, N., Barazangi, M., Isacks, B.L., 1993. Lithospheric structure of Tibet and western North America: mechanisms of uplift and a comparative study. J. Geophys. Res. 98, 1997-2016.

Blümling, G., Prodehl, C., 1983. Crustal structure beneath the eastern part of the Coast Ranges (Diablo Range) of central California from explosion seismics and near-earthquake data. In: Ansorge, J., Mereu, R.F. (Eds.), Probing the Earth's Lithosphere. Phys. Earth Planet. Inter., vol. 31, pp. 313-326.

Brown, L.D., et al., 1996. Bright spots, structure, and magmatism in southern Tibet from INDEPTH seismic reflection profiling. Science 274, 1688-1690.

Burke, K., Sengör, C., 1986. Tectonic escape in the evolution of the continental crust. In: Barazangi, M., Brown, L.D. (Eds.), Reflection Seismology: the Continental Crust. AGU, Washington, DC, Geodynamic Series, vol. 14, pp. 41-53.

Coward, M.P., Kidd, W.S.F., Yun, P., Shackelton, R.M., Hu, Z., 1988. The structure of the 1985 Tibet geotraverse, Lhasa to Golmud. Philos. Trans. R. Soc. Lond. Ser. A: Math. Phys. Sci. 327, 327-336.

Crotwell, P., Randall, G.R., McNamara, D.E., Owens, T.J., 1995. Frequency dependent propagation of regional $\mathrm{Sn}$ within the Tibetan Plateau. EOS Trans. AGU 76 (17), S201 (Spring Meeting Suppl.).

Dewey, J.F., Burke, K.C., 1973. Tibet, Variscan and Precambrian reactivation: products of continental collision. J. Geol. 81, 683-692.

Dewey, J.F., Shackleton, R.M., Chang, C., Sun, Y., 1988. The tectonic evolution of the Tibetan Plateau. Philos. Trans. R. Soc. Lond. A327, 379-413.

England, P., Houseman, G., 1986. Finite strain calculations of continental deformation: 2. Comparison with the India-Asia collision zone. J. Geophys. Res. 91, 3664-3676.

Fuchs, K., 1983. Recently formed elastic anisotropy and petrological models for the continental subcrustal lithosphere in southern Germany. Phys. Earth Planet. Int. 31, 93-118.

Furlong, K.P., Fountain, D.M., 1986. Continental crustal underplating: thermal considerations and seismic-petrologic consequences. J. Geophys. Res. 91, 8285-8294.

Galvé, A., et al., 2002. Modes of raising northeastern Tibet probed by explosion seismology. Earth Planet. Sci. Lett. 203, 35-43.

Girardeau, J., Marcoux, J., Allegre, C.J., Bassoullet, J.P., Tang, Y., Xiao, Y., Wang, X., 1998. Tectonic environment and geodynamic significance of the Neo-Cimmarian Donquiao Ophiolite, Banggong-Nujiang Suture zone, Tibet. Nature 307, 27-31.

Green, D.H., Ringwood, A.E., 1967. An experimental investigation of the gabbro to eclogite transformation and its petrological applications. Geochim. Cosmochim. Acta 31, 767-833.

Haines, S.S., Klemperer, S.L., Brown, L.D., Jingru, G., Mechie, J., Meissner, R., Ross, A.,Wenjin, Z., 2003. INDEPTH III seismic data: From surface observations to deep crustal process in Tibet. Tectonics 22 (1), 1001, 1-20.

Henry, P., Le Pichon, X., Goffé, B., 1997. Kinematic, thermal and petrological model of the Himalaya: constraints related to metamorphism within the underthrust Indian crust and topographic elevation. Tectonophysics 273, 31-56.

Herquel, G., Wittlinger, G., Guilbert, J., 1995. Anisotropy and crustal thickness of northern Tibet: new constraints for tectonic modeling. Geophys. Res. Lett. 22, 1925-1928.

Hirn, A., Nercessian, A., Sapin, M., Jobert, G., Xin, X.Z., Yuan, G.E., Yuan, L.D., Wen, T.J., 1984. Lhasa Block and bordering sutures - a continuation of a $500 \mathrm{~km}$ Moho traverse through Tibet. Nature 307, 25-27.

Hirn, A., et al., 1995. Seismic anisotropy as an indicator of mantle flow beneath the Himalaya and Tibet. Nature 375, 571-574.

Huang, W.-Ch., et al., 2000. Seismic polarization anisotropy beneath the central Tibetan Plateau. J. Geophys. Res. 105, 27979-27989.

INDEPTH Project Team, Zhao, W., Nelson, K.D., 1993. Deep seis- 
mic reflection evidence for continental underthrusting beneath southern Tibet. Nature 366, 557-559.

Ito, K., Kennedy, G.C., 1971. An experimental study of the basaltgarnet-eclogite transition. In: Peakock, Y.G. (Ed.), The Structure and Physical Properties of the Earth's Crust. Geophys. Mono. Series, vol. 14. AGU, Washington, DC, pp. 303-314.

Jia, S., Cao, X., Jia, J., 1981. The P wave travel times and upper mantle structure of the Tibetan Plateau. N. W. Seism. J. 3, $27-34$.

Kern, H., Burlini, L., Ashchepko, I.V., 1996. Fabric-related anisotropy in upper mantle xenoliths: evidence from measurements and calculations. Phys. Earth Planet. Inter. 95, 195-209.

Kind, R., et al., 2002. Comprehensive seismic images o the crust and upper mantle beneath Tibet. Science 298, 1219-1221.

Kola-Ojo, O., Meissner, R., 2001. Southern Tibet: its deep structure and some tectonic implications. J. Asian Earth, 240-256.

Kosarev, G., Kind, R., Sobolev, S., Yuan, X., Hanka, W., Oreshin, S., 1999. Seismic evidence for a detached Indian lithospheric mantle beneath Tibet. Science 5406 (283), 1306-1309.

Langin, W.R., Brown, L.D., Sandvol, E.A., 2003. Seismicity of central Tibet from Project INDEPTH III seismic recordings. Bull. Seismol. Soc. Am. 93 (5), 2146-2159.

Le Pichon, X., Henry, P., Goffe, B., 1997. Uplift of Tibet: from eclogites to granulites-implications for the Andean Plateau and the Variscan belt. Tectonophysics 273, 57-76.

Makowski, Y., Klemperer, S., 1999. Measuring the seismic properties of Tibetan bright spots: evidence for free aqueous fluids in the Tibetan middle crust. J. Geophys. Res. 104, 10795-10825.

McNamara, D.E., Ovens, T.J., Silver, P., Wu, F., 1994. Shear wave anisotropy beneath the Tibetan Plateau. J. Geophys. Res. 99, $13655-13665$.

McNamara, D.E., Owens, T.J., Walter, W.R., 1995. Observations of regional phase propagation across the Tibetan Plateau. J. Geophys. Res. 100, 22215-22229.

McNamara, D.E., Walter, W.R., Owens, T.J., Ammon, C.J., 1997. Upper mantle velocity structure beneath the Tibetan Plateau from $\mathrm{P}_{\mathrm{n}}$ travel time tomography. J. Geophys. Res. 102, $483-505$.

Meissner, R., 1996. Faults and folds, fact and fiction. Tectonophysics 264, 279-293.

Meissner, R., Mooney, W.D., 1998. Weakness of the lower continental crust: a condition for delamination, uplift, and escape. Tectonophysics 296, 47-60.

Meissner, R., Strehlau, J., 1982. Limits of stresses in continental crusts and their relation to depth-frequency distribution of shallow earthquakes. Tectonics 1, 73-89.

Meissner, R., Mooney, W.D., Artemieva, I., 2002. Seismic anisotropy and mantle creep in young orogens. Geophys. J. Int. 148, $1-17$.

Molnar, P., Tapponier, P., 1975. Cenozoic tectonics of Asia: effects of a continental collision. Science 189, 419-426.

Mooney, W.D., Prodehl, C. (Eds.), 1984. Proceedings of the 1980 workshop of the International Ass. of Seismology and Physics of he Earth's interior on the seismic modeling of laterally varying structures. U.S. Geol. Surv. Circ., vol. 937. 158 pp.

Müller, G., 1985. The reflectivity method: a tutorial. J. Geophys. Res. 58, 153-174.

Nelson, K.D., et al., 1996. Partially molten middle crust beneath southern Tibet: synthesis of project INDEPTH results. Science 274, 1684-1688.

Park, J., Levin, V., 2002. Seismic anisotropy: tracing plate dynamics in the mantle. Science 296, 485-489.

Powel, C.M., 1986. Continental underplating model for the rise of the Tibetan Plateau. Earth Planet. Sci. Lett. 81, 79-94.

Powel, C.M., Conaghan, P.J., 1973. Plate tectonics and the Himalaya. Earth Planet. Sci. Lett. 20, 1-12.

Rapine, R., Tilmann, F., West, M., Ni, J., Rodgers, A., 2003. Crustal structure of northern and western Tibet from surface wave dispersion analysis. J. Geophys. Res. 108 (B2), 2120-2129.

Ratschbacher, L., 1996. Kinematics of Tibet. Z. Dtsch. Geol. Ges. $147,427-434$.

Ringwood, A.E., Green, D.H., 1966. An experimental investigation of the gabbro-eclogite transformation and some geophysical applications. Tectonophysics 3, 383-427.

Sapin, M., Hirn, A., 1997. Seismic structure and evidence for eclogitization during the Himalayan convergence. Tectonophysics 273, 17-30.

Smith, G.P., Ekström, G., 1999. A global study of $P_{n}$ anisotropy beneath continents. J. Geophys. Res. 104, 963-980.

Tapponnier, P., 1981. The Tibetan side of the India-Eurasia collision. Nature 294, 405-410.

Tapponnier, P., 1990. The Ailao Shan-Red River metamorphic belt: tertiary left-lateral shear between Indochina and South China. Nature 294, 405-410.

Tapponier, O., Zhiqin, X., Roger, F., Meyer, B., Arnaud, N., Wittlinger, G., Jinsul, Y., 2001. Oblique stepwise rise and growth of the Tibet Plateau. Science 294, 1671-1677.

Tilmann, F., Ni, J., INDEPTH III team, 2002. The India Asia collision zone in the mantle beneath central Tibet revealed by P wave tomography. Geophys. Res. Abstr., 2th EGS, Nice, p. 86.

Tilmann, F.J., Ni, J. INDEPTH III Seismic Team, 2003. Seismic imaging of the downwelling Indian lithosphere beneath central Tibet. Science 300, 1424-1427.

Van der Voerd, J., et al., 2002. Uniform postglacial slip-rate along the central $600 \mathrm{~km}$ of the Kunlun Fault (Tibet), from 2-1, $10 \mathrm{Be}$, and 1-dating of riser offsets, and climatic origin of he regional morphology. Geophys. J. Int. 148, 356-388.

Vergné, J., Wittlinger, G., Hui, Q., Tapponier, P., Poupinet, G., Mei, J., Herquel, G., Paul, A., 2002. Seismic evidence for stepwise thickening of the crust across the NE Tibetan Plateau. Earth Planet. Sci. Lett. 203, 25-33.

Vinnik, L.P., Makeyeva, L.I., Milev, A., Usenko, A.Y., 1992. Global pattern of azimuthal anisotropy and deformations in the continental mantle. Geophys. J. Int. 111, 433-447.

Wang, Q., et al., 2001. Present-day crustal deformation in China constrained by global positioning system measurements. Science 294, 574-577.

Westaway, R., 1995. Crustal volume balance during the IndiaEurasia collision and altitude of the Tibetan Plateau: a working hypothesis. J. Geophys. Res. 100, 15173-15192.

Yin, A., Harrison, T.M., 2000. Geologic evolution of the Himalayan-Tibetan orogen. Annu. Rev. Earth Planet. Sci. Lett. 28, $211-280$.

Yuan, X., 1999. Teleseismic receiver functuin study and its appli- 
cation in Tibet and the Central Andes; Ph.D. thesis. GeoCenter Potsdam, Sci. Technical Report STR00/10. 146 pp.

Yuan, X., Ni, J., Kind, R., Mechie, J., Sandvol, E., 1997. Lithospheric and upper mantle structure of southern Tibet from a seismological passive source experiment. J. Geophys. Res. 102, 27491-27500.

Zelt, C.A., Smith, R.B., 1992. Seismic travel time inversion for 2-D crustal velocity structure. Geophys. J. Int. 108, 16-34.

Zhao, W.L., Morgan, W.J., 1985. Uplift of the Tibetan Plateau. Tectonics 4, 359-559.
Zhao, W.L., Morgan, W.J., 1987. Injection of Indian crust into Tibetan lower crust: a two-dimensional finite element model study. Tectonics 6, 489-504.

Zhao, W., Nelson, K.D., and then INDEPTH Team, 1993. Deep seismic-reflection evidence of continental underthrusting beneath southern Tibet. Nature 366, 557-559.

Zhao, W., et al., 2001. Crustal structure of central Tibet as derived from project INDEPTH III wide angle data. Geophys. J. Int. $145,486-498$. 